\title{
Plunging into a world? \\ A novel approach to undergraduates' metaphors of reading
}

\author{
Ingrid Scharlau $^{\mathrm{a}}$, Miriam Körber ${ }^{\mathrm{a}}$ and Andrea Karsten ${ }^{\mathrm{a}}$

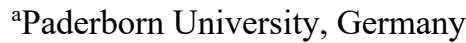 \\ Article received 19 August 2019/Article revised 10 October / Accepted 15 October / Available online 22 November
}

\begin{abstract}
Although there is considerable research on and knowledge about students' conceptualizations of learning or academic practices and skills, the variability of these conceptualizations has been consistently neglected. In the present study, we address this variability in the field of academic reading with the help of a novel approach. Drawing on qualitative metaphor analysis, we report a detailed system of students' conceptual metaphors of reading. Our specific methodological approach to identify the structure of these conceptual metaphors allows to analyze subjective agency on a lexical as well as grammatical level. The conceptual metaphors we identified by this method are markedly variable, although they create an overall impression of medium to low agency, that is a reader who is only weakly active or potent. Interrater reliability of the coding system was very good. We also report and analyze the frequency of the conceptual metaphors in a sample of 143 texts written by bachelor students.
\end{abstract}

Keywords: metaphor, conceptual metaphor, metaphor analysis, academic reading, transitivity 


\section{Introduction}

Academic reading and writing are challenging activities at the core of learning. Many factors contribute to their difficulty: they comprise different low- to high-level skills that have to be learned and used at appropriate stages or points in time and with the appropriate effort, and they presuppose adequate awareness of one's doing as well as self-regulation of cognition, motivation and behavior. Furthermore, texts vary considerably across different disciplines or discourse communities so that different reading or writing practices are necessary.

So far, the focus of research has been more on academic writing. However, in higher education and science, reading and writing are tightly intertwined (e.g. in the task of discourse synthesis; Spivey 1997, Boscolo \& Mason, 2001, Wiley \& Voss, 1999, O’Hara et al., 2002; for a more general view see, e.g., Shanahan, 2015) and similarly complex. Some problems of academic writing may result from problems with reading, for instance inadequate reading strategies, low reading motivation or inappropriate reading goals.

In the present paper, we take a look at a factor that possibly contributes to the problems of academic reading but has rarely been recognized and even less frequently tackled rigorously in recent research - the way in which members of academia talk and think about reading and writing. For instance, a German advice book for students addresses the approach of problem-oriented reading in the following way: "It is concentrated reading, that aims less at forming scientific judgment but at a direct involvement with a thematic field and the utilization of the read material for one's own argumentation" (Krajewski 2015, p. 52; translation IS). The words Krajewski uses, German "ausbilden" (forming), "Auseinandersetzung" (involvement) and "Verwendung" (utilization) all imply - and are likely meant to imply - an active person who handles objects. Interestingly, though, the sentence does not mention the acting person and does not realize the activities as verbs - there is no student who reads and wants to achieve something, judges, grapples with a field or argues and thereto uses others' words.

To give a different example of such metaphor use, in the fourth edition of the "Psychologist's companion" addressed at undergraduates as well as graduates, the author writes: "Pursue the references that your teacher and textbook cite, and pursue the references most frequently cited in these references. By digging into the literature on the topic, you will acquire a deeper understanding of the issues that are the focus of psychological research" (Sternberg, 2005, p. 36). There are three prominent metaphors in this quote, PURSUING, which evokes the image of reading as a path or motion, DIGGING, drawing on exhausting work with material and evoking a distinct spatial dimension (deep vs. shallow), and ACQUIRING which implies that there are things to be collected. In contrast to the first example, the grammatical form is congruent with the activity: Sternberg directly addresses a student who pursues, digs and acquires.

Metaphors are also present in more academic texts. For instance Hermida (2009), drawing on earlier research by Bowden and Marton (2000), writes:

„A surface approach to reading is the tacit acceptance of information contained in the text. [...] The deep reader focuses on the author's message, on the ideas she is trying to convey, the line of argument, and the structure of the argument. The reader makes connections to already known concepts and principles and uses this understanding for problem solving in new contexts" (Hernandez, 2009, p. 21).

Most of the metaphors in this text are so common that they easily go unrecognized, for instance the idea that texts CONTAIN something (information, ideas etc., often depicted as things that can be linked to each other or not), the contrast between SURFACE and DEPTH, the image of the LINE of an argument. Interestingly, in terms of metaphors, the two approaches contrasted by the author seem to be less different than one might think at first sight: In both cases, texts are about things that can be conveyed or taken up and assembled. Deep readers actively link these 'bits of text' and may construct new meaning, but both they and surface readers act upon the bits. There is another metaphor in the quote that draws its meaning from a different source - NEGOTIATING -, but it is mentioned only once.

Why should metaphors matter? We would argue that it generally matters in higher education how we speak about issues and even more so in educational settings, but there is a more straightforward reason for the importance of metaphor. The cognitive linguists Lakoff and Johnson (1980) were among the first to claim that 
all thinking is metaphorically structured (e.g. Lakoff \& Johnson 1980; Landau, Meier \& Keefer, 2010). Whether one follows this strong (and controversial) thesis or not, conceptual metaphors can be regarded as cognitive tools (Gibbs, 1994; Kövecses, 2002, 2010) that allow to understand something new or abstract (the so-called target domain) in terms of something known or concrete (the source domain). That is, students trying to understand academic reading may do so with the tools of metaphors - their own, their teachers', those in textbooks or other sources.

Accordingly, cognitive linguistic studies have shown that linguistic metaphors, superficial as they might seem at first sight, can give insight into the conceptual systems of speakers. However, the linguistic forms used by speakers of a given community also shape semantic concepts by highlighting certain characteristics and downplaying others. For instance, imagining reading as linking bits of information highlights the cognitive effort of understanding different parts of texts, but downplays the author as well as the text as a whole.

"According to cognitive linguists, language not only reflects conceptual structure, but can also give rise to conceptualisation. It appears that the ways in which different languages 'cut up' and 'label' the world can differentially influence non-linguistic thought and action” (Evans \& Green, 2006, p. 101).

This holds true not only for the language of a given society, but also for the way more fine-grained speech communities (like academic discourse communities) speak. For example, the way a computer scientist conceptualizes reading may differ from the way a sociologist does. This is due to both differing experiences with reading in the respective discipline and the way the academic community typically talks about reading.

Taking this stance, it is likely that metaphors shape thinking about academic reading and writing and thereby may influence writers' feelings, strategies and behavior. Generally, research in the conceptual-metaphor framework has shown that metaphors influence what persons attend to or which information they remember as well as their perception and attitudes (for an overview see Landau et al., 2010). One thus can draw the presumption that metaphor has its share not only in clarifying as well as obscuring practices in academia, but also some influence on actual behavior. This opens up a wide range of possibilities for metaphor-related didactic action in the field of teaching academic writing and reading.

To give an example, Bean (2011, p. 138) suggests to use metaphor games and so-called extended analogies in order to understand academic writing. In these exercises, the students compare writing to familiar experiences or things ("Writing is like ..." or "Journal writing is like ..., but formal essay writing is like ..."). Similarly, in the decoding-the-disciplines framework, a general approach to identifying and overcoming discipline-specific bottlenecks to student learning (e.g., Middendorf \& Shopkow, 2018; Pace, 2017), metaphors are used to unpack abstract and coarse descriptions of tasks, for instance "critical reading". The metaphors are chosen so that they detail what an expert would do in the respective situation. Teachers model this behavior including its steps with the help of and in the frame of the metaphor. For instance teachers could model their recursive reading strategies with the help of the metaphor of a spiral, returning repeatedly to the same sentence in a text to evaluate it again and again on the basis of their growing understanding of the text.

To sum up, there is evidence that metaphors matter for academic engagement, are widely used in discourse on academic practices and seem to - often inadvertently - shape how students understand these practices and shape their behavior. So far, however, there are few methodologically and theoretically rigorous studies on such metaphors. In the present study, we address this gap in the field of academic reading. We collect a large sample of metaphors of reading from undergraduate students and use several approaches to cluster and understand them. Such a system, once established, could be used to attend to inadvertent metaphors in academic discourse or to choose helpful metaphors, but also to study the role of metaphors for academic success, matches or mismatches between the metaphors of staff and students, and to compare different disciplines or describe changes by academic enculturation. 


\section{Approach to metaphors}

In contrast to earlier studies, our aim is to put the rich content of metaphor into focus in order to take a differentiated view on the topic. As mentioned above, metaphor use and recognition are important cognitive strategies because they allow to understand new or abstract concepts in terms of interactions with the physical world or bodily states, for instance as taking things up or immersing oneself into a book. Many studies analyzed those metaphors in terms of a few, often only two or three, underlying broad categories (Paulson \& Armstrong, 2011; Paulson \& Theado, 2015; Saban, Kocbeker \& Saban, 2007; Wegner \& Nückles, 2015a, 2015b) - such as learning as uptake of pre-existing ideas, learning as problem solving and learning as development of personality (Wegner \& Nückles, 2016). However, people use many more metaphors than just these, and this variety is not only across persons (and groups such as different student groups or different disciplines and cultures), but may also arise within persons, for instance when talking to different others or in different situations or faced with different tasks. With the current study, we want to identify a wide and as comprehensive as possible range of metaphors that students spontaneously use for academic reading and to explore whether there is indeed substantial heterogeneity in a structural and cognitively relevant sense.

Straightforward metaphoricity is visible on the lexical level, i.e. in the metaphorically used nouns, verbs and adjectives that are related to aspects of our everyday world and lives and with which people describe more abstract concepts. For instance, depicting reading as immersion into a world would have implications different from reading as opening a treasure chest, for instance in terms of activities, size and 'thinginess'. The sources will point out, downplay or even conceal different aspects of the target domain; this is what Lakoff and Johnson (1980) call the hiding and highlighting aspect of metaphors. To give an example, one of the most famous metaphors used in Western culture is Heraclitus' saying that no man can step into the same river twice. The German philosopher Blumenberg $(2012$, p. 103) noted that this metaphor highlights that reality is everchanging, but downplays or even hides that stepping into a river and descending from it imply a bank that does not change and even is the same bank farther downwards the stream.

While the bigger part of studies on metaphors in different domains focuses on this lexical aspect, we take a more cognitive-linguistically oriented stance and additionally attend to metaphoric conceptualizations on a grammatical level. In practice, this means that we analyze students' conceptions of academic reading also with regard to questions such as how much agency is attributed to readers, if the focus lies on the products and outcomes of reading or the processes and activities, and how purpose-oriented the latter are. These conceptualizations are expressed less by the choice of explicit metaphors (that is, which metaphors participants choose to conceptualize reading) but rather through the linguistic constructions in metaphorical utterances (that is, which qualities the specific metaphorical expressions attribute to the actors and the activity of reading).

More systematically, our novel approach is to suggest that transitivity - the effectiveness with which an action takes place as it is semantically construed and linguistically expressed (Hopper \& Thompson, 1980) - is an important aspect of the transfer of meaning that is inherent in metaphors, at least those used for human action and cognition. Hopper and Thompson list 11 components that can be rated as - mostly - high or low or present or not present and that contribute to the overall degree of transitivity. These are

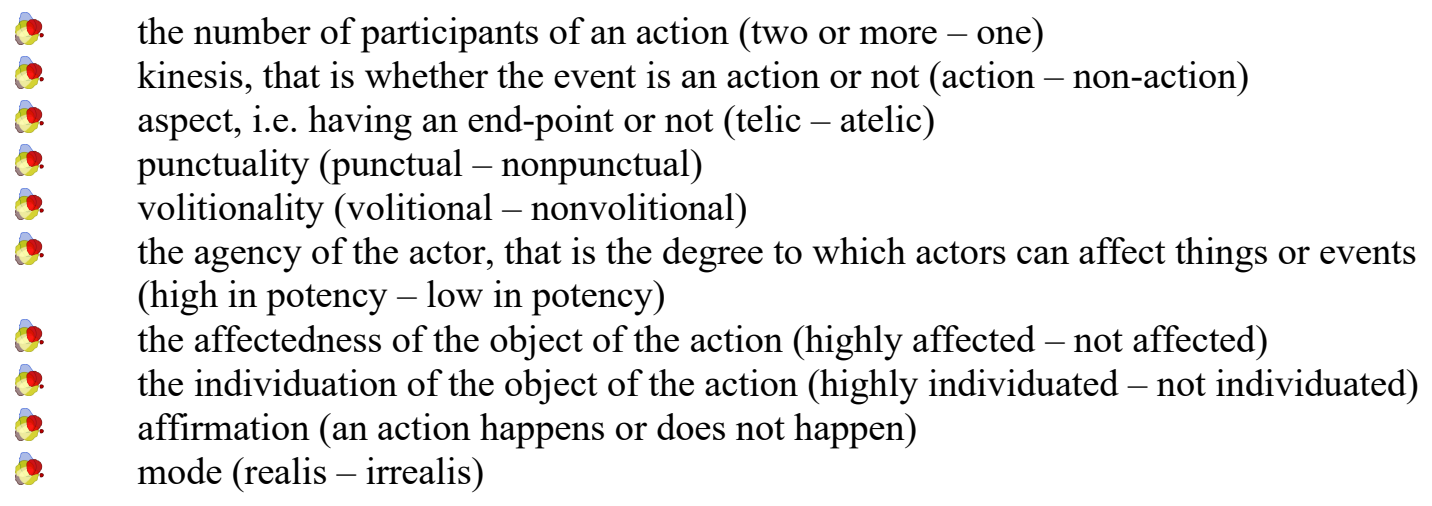


These components contain important information about activities, and we used them to characterize the conceptual metaphors we identified in the material, thus specifying Lakoff and Johnson's (1980) rather vague notion of the structure of metaphors.

The transitivity status of a metaphor can be determined on two levels. One is the level of conceptual metaphors, focusing on the typical transitivity of a metaphorical image. For example, describing reading as IMMERSING ONESELF INTO A WORLD implies little agency whereas reading as COMBINING THINGS INTO A WHOLE highlights volitionality and purposiveness, relatively independent from the exact expressions the speaker uses to invoke these conceptual metaphors. The choice of a conceptual metaphor is thus likely to feed into the way in which specific metaphoric expressions are construed on a grammatical level. Therefore, in many cases, specific utterances comply with the typical transitivity of a metaphorical source domain. However, they may as well be inconsistent with it, for instance if a verb such as forming, which implies high agency, was used with a different actor than the reader, for example describing reading as SOMETHING FORMING IN ONE'S MIND.

This distinction has consequences for analyzing metaphors. A purely grammatical approach to transitivity on the utterance level would attest high or low transitivity to a linguistic expression regardless of who or what the agent of the utterance is. Slightly departing from this, we are going to focus on the reader-as-agent. Thus, we will speak of high or low transitivity of a metaphor looking at the degree to which the reader as our agent in question is conceptualized as active, purposeful etc. This means to always consider both the level of conceptual metaphor and at the content of the metaphor as well as the grammatical form on the utterance level. Determining the transitivity status of a metaphor in this way helps us to see if the reader is depicted as agent (or non-agent) both by the choice of metaphor and the grammatical realization.

To sum up, our study addresses students' conceptualizations of academic reading inherent in their metaphors for this practice. We are breaking new ground in so far as we, firstly, want to identify and preserve the heterogeneity of metaphors as far as possible, and, secondly, choose a structured approach to the analysis of conceptual metaphors based on the agency of the reader.

\section{Methods}

Participants. Participants were 143 students enrolled in bachelor programs (teacher training and Arts and Humanities) at Paderborn University, North-Rhine-Westphalia, Germany, a mid-sized university with approximately 20.000 students many of which are enrolled in teacher training programs. All students gave fully informed written consent. The study was approved by the ethics committee of Paderborn University. ${ }^{1}$

Procedure and materials. Data were collected in four classes. For the teacher training students (two of the classes), the seminar is part of the bachelor module Introduction to education studies. Its focus is on reading and analyzing psychological research on motivation. The students aim for high and middle school and business school (Gymnasium/Gesamtschule, Haupt-, Real und Gesamtschule, Berufskolleg) and should attend the class in their first or second semester although many do so later in their course of studies. The students in Arts and Humanities (the other two of the classes) are enrolled in a bachelor program with two subject areas from the humanities or social sciences (e.g., education, German literature, British/American literature, philosophy). Here, the seminar is part of a so-called orientation module. The module covers key skills and the seminar topic was an interdisciplinary introduction to academic reading and writing.

In the first session of the seminar, we handed out a sheet with the following instruction: "(1) Please complete this sentence with the image, analogy, or metaphor which comes to mind first. Reading is like ... If you come up with several images, analogies, or metaphors, name these. (2) Describe or explain your image or metaphor in a few sentences. For instance you can describe similarities between reading and your image or

\footnotetext{
${ }^{1}$ As we did not plan to analyze the metaphors depending on specific individual characteristics such as age, study semester, subject areas, gender etc., and we did not want to induce any expectations about the importance of these features in the students' minds, we did not record this information.
} 
motivate why you have chosen it.“2 The students completed the sheets in a self-paced manner and had as much time for writing down their answers as they wanted.

The instruction explicitly required a source metaphor and an explanation or description, a method that has successfully used by, for instance, Paulson and Armstrong (2011), Saban, Kocbeker and Saban (2007) or Wegner and Nückles (2015a, 2015b, 2016). The texts were typed before analysis so that handwriting information was removed. No personal information except for first language(s) was collected.

The instruction addressed reading in a generic manner instead of asking for academic or scientific reading. We chose this approach for several reasons. Firstly, the metaphors were sampled in reading-intensive seminars at university. Contextual cues thus were in favor of academic reading. Secondly, there are some drawbacks of more specific instructions that would have to be carefully weighed against generic instructions. For instance talking about academic reading might point the students toward the expectation that there is a difference between kinds of reading that they might not have found relevant in the first place. In a preliminary study in which we asked for metaphors of academic reading and writing, the answers tended towards definitions instead of metaphors, which would undermine the whole approach of metaphor research. Thirdly, and most importantly, we do not yet know how generic or specific metaphorical concepts of reading are. We are not aware of any research that addresses this question. It is possible that students have different concepts for different genres (such as scholarly texts, novel, news, etc.) or contexts (such as at home, at work, at university), but it is also possible that they have a generic concept or a hierarchy of generic to specific metaphors (similar to general to specific self-concepts or self-efficacy). Finally, many texts and much talk addressing academic practices at German universities are similarly generic and it is exactly the spontaneous metaphors that are activated in such situations that we are interested in. However, we cannot make sure that the generic approach misses some important metaphors.

\subsection{Analysis of metaphors}

Text examples. In order to convey the 'flavor' of the texts, we will first give a few examples. One student, for instance, wrote: "Reading is like a wall. Like standing in front of a wall and not really knowing exactly what is behind. It's the same with a text/book. Only when you look behind the wall, into the text, you know exactly what it is about. If you are inside reading a text/book, then this is also a wall that keeps many other external influences away, if you have sunk yourself completely into the text/book" (132). This is a text of rather strong metaphoricity, as is the next example that however gives a very different overall impression: „Reading is like lying in a hammock and letting your soul 'dangle'. You can switch off while reading and flee from everyday life. It is exactly the same when you lie in a hammock and think of nothing or sink into the world of thoughts" (123).

Some writers explicitly used and explained several metaphors, as in the next example. „Reading is like immersing yourself in another world. Reading is like watching a movie, only more detailed. Reading is like home. SESPR Reading brings you into a completely new environment. You can leave your everyday life behind you and come to rest. I chose this picture because it entices me to immerse myself in a new story and experience it 'up close'. I chose the term 'home' because reading is something comfortable for me. It feels familiar and gives me a good feeling" (113).

Some students explored a metaphor somewhat thoroughly: "swimming in the sea. The sea consists on the one hand of unknown depths, but on the other hand also of shallow shore zones. If one swims in the sea, one never knows where the next sandbank comes or where it suddenly gets deeper. This is exactly the same when reading. There are simple, easy and shallow places, but also deeper places. Reading immerses you in the unknown" (81).

Other texts were short and more difficult to interpret and understand. One example is "Immersing oneself in another world - an adventure - one disappears from one's own reality - perceives other feelings and things - one feels oneself into other figures, forgets oneself for the blink of an eye - exciting" (35). There were

\footnotetext{
${ }^{2}$ The students were also asked for metaphors of writing and motivation. These will be analyzed in other papers (Scharlau, Rohlfing \& Karsten, subm.).
} 
also some rather vague and nonimaginative texts, such as: "Reading is like learning by heart. I chose this picture because I read the information over and over again while learning by heart. By reading I can keep the information better. If I read out key points aloud, it is even easier for me to keep them" (110).

Unit of analysis. As the texts were short and dense, we decided to use the text as unit of analysis (Wegner \& Nückles, 2015a, 2015b, used a similar task and made the same decision). An individual text consisted of several phrases, the naming of source metaphor and at least one phrase with a description/explanation. Metaphors named in the source and in the description were not necessarily consistent, nor did metaphors in different phrases of the same text. All metaphors were coded independently of whether there was a congruent overall picture in the text of an individual participant.

Development of the coding system. The main goal of the present paper is to develop a system of conceptual metaphors of reading. We first identified metaphorical expressions in the texts and then assigned them to a conceptual metaphor (e.g. Schmitt, 2017). To give an example, one student wrote (metaphorical expressions underlined): "Reading is like opening a treasure chest. Every book you open brings new knowledge or new insight. At the same time, however, you will also find treasures in novels that can help you

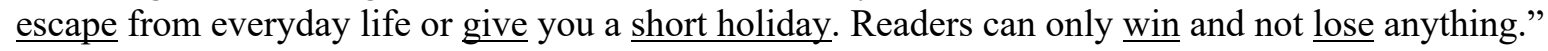

In many cases, identification of metaphorical concepts from metaphorical expressions was straightforward, as in the following example: "plunging into another world. For me, reading is like immersing oneself in another world, because I can forget everything around me when I read an exciting book." Here, we identified the conceptual metaphor of PLUNGING and the conceptual metaphor of FORGETTING. These metaphors are congruent, but not conceptually identical. In other cases, identification was less straightforward, as in the following example: "A deluge of information. On the one hand, reading is a deluge of information, because there is always a lot of information in what one reads. This information then patters on you like a deluge." This example is more difficult to interpret and was finally identified as BEING FLOODED. As it was the single example of reading as being flooded with elements in the sample of our texts, we decided to list it as an idiosyncratic metaphor.

Having identified possible conceptual metaphors, we used the two approaches from the literature mentioned above to describe them. The first, lexical approach is closely related to the structural approach of Lakoff and Johnson (1980) and is captured in the method of qualitative metaphor analysis (Schmitt, 2017). Here, the source domain and its conceptual content were described. In the above examples this would be plunging into something, forgetting something and being flooded. The second approach draws on transitivity analysis (Hopper \& Thompson, 1980). For each conceptual metaphor, we described the transitivity according to nine of the eleven components of transitivity mentioned in the introduction. (Mode and aspect were not used because they were fixed as realis/indicative and non-negation by our task: The stem completion "Reading is like ..." did not offer to answer "is not like" or "might be like".) PLUNGING, for instance involves only one person. It is rather volitional, but punctual, and there is no individuated object of the action - it affects the person rather than an object. There is no clear telos or end-point. The person is at most medium in potency. Overall, thus, transitivity is medium.

In the following, we describe transitivity mostly on the level of the conceptual metaphors. In many cases and for the reasons given above, conceptual transitivity was consistent with the grammatical constructions in the texts. If however, the specific utterances did not correspond with conceptual transitivity, for instance because they used the passive voice, an indefinite object such as 'something' or no object at all, we included this in the descriptions of the metaphors.

Transitivity analysis was especially effective in separating different conceptual metaphors that draw on the same source domain. For example, the activity of moving appeared in different forms and with different degrees of transitivity, as strongly volitional motion (for instance walking along a path) or as being moved (for instance riding on a roller coaster). These instances could be differentiated by their transitivity.

With the help of these two steps, we identified a large system of possible conceptual metaphors that is presented below. We combined similar metaphors into metaphorical systems that capture the essence of their members in terms of source domain and transitivity. 
The conceptual metaphors were developed by one of the authors (IS) and later discussed in the whole team of authors. While coding, the coders could add further categories. Definitions and examples of metaphors were written down in a short manual. Then, two independent coders (SB: not involved in developing the code system, MK: involved only in adding missing codes) coded 20 texts and compared and discussed their results. The other 123 texts were coded independently.

Interpretation and coding were done in German; codes were later translated into English. In some cases, translation was difficult because the semantically most appropriate translation was reflexive in one language and not reflexive in the other, or transitive in one language, but intransitive in the other. For instance, German "in etwas eintauchen" is not reflexive whereas its English equivalent "immersing oneself into sth" is; the German word for "switching off, "abschalten", can be used intransitively meaning that a person relaxes, but this is not the case in English. Because of our focus on transitivity, we always chose the grammatically congruent translation and discuss the exact semanticity of the German wording where necessary.

\section{Results}

\subsection{Qualitative results: The coding system}

Overall, 66 conceptual metaphors were identified. We bundled similar metaphors into groups with a distinct conceptual characteristic. These groups are handling things, moving in or out, moving around, seeing/opening and being acted upon. In contrast to earlier studies (e.g., Paulson \& Armstrong, 2011; Wegner \& Nückles 2015, 2016), we do not integrate the conceptual metaphors within such a group into one overarching conceptual metaphor - the names of the groups are convenient descriptions, not metaphors. The reason is that there is still considerable variability within each group in terms of agency and conceptualization and we want to preserve this variability.

The following paragraphs describe the conceptual groups and their transitivity. The definitions of the single conceptual metaphors can be found in Appendix A, each with an example sentence and a short description of their conceptual content and transitivity. Furthermore, the most frequent conceptual metaphor within each group is described along with the overall description of the group.

\subsubsection{Handling things: Solidification metaphors}

This group of conceptual metaphors (see Table 1) is defined by an actor who handles things. One common example was taking up, as in the following text (the most frequent conceptual metaphor is discussed below): "Reading is breathing knowledge. When you read texts, you always take something up, whether you like it or not" (62).

Conceptually, such handling of things would imply high transitivity. Interestingly though, the specific metaphors we found and their use in the texts was more of medium than of high transitivity, as in the example above in which the uptake is depicted as rather involuntary. Table 1 gives an overview of the metaphors and their transitivity aspects.

The handling, an action, was often telic and volitional, but in other cases lacked these properties. Although an individuated object would suggest itself in the context of handling, it often was not individuated in the texts. For instance, students often wrote that "something" was taken up. If included explicitly, the object often was an abstract concept, such as impressions, ideas or knowledge. Although the actor is depicted as high in potency, the object is not necessarily affected - on the contrary: it can be unaffected as in HOLDING, weakly affected as in COMBINING, strongly affected as in PROCESSING or even coming into existence as in CREATING. Other persons are conspicuously absent from the descriptions. Only two metaphors (RECEIVING and TRANSPORTING) imply other persons, but these were not mentioned. The action is often extended in time, but can also be punctual. 
Overall, thus, transitivity can be described as medium in these metaphors, FINDING, RECEIVING and STH FORMS being three exceptions with very low agency, and CREATING and PROCESSING two exceptions with very high agency.

The most frequent metaphor in this group was STH FORMS. A typical example is: "While reading, images form in the head" (32). This metaphor may not seem a genuine part of the "handling things" system because nothing is handled here, but it fits the solidification aspect which is inherent in many of the metaphors. Its transitivity is largely opposite to the other members of this system: Instead of a person handling something and changing its features, here the thing changes its features by itself. In very many cases, the object that forms is an image, that is a faintly individuated object.

Table 1

Handling things: Solidification metaphors and their transitivity aspects. The sign "+" denotes the presence of an aspect, "- "its absence. A question mark indicates that the feature is unclear, " \pm " signals that the feature differed in the texts. If a sign is put into brackets, the feature is present, but not strongly so and may be of limited value for characterizing the metaphor

\begin{tabular}{|l|l|l|l|l|l|l|l|l|}
\hline & action & telic & $\begin{array}{l}\text { temp. ex- } \\
\text { tended }\end{array}$ & $\begin{array}{l}\text { volitio- } \\
\text { nal }\end{array}$ & $\begin{array}{l}\text { high po- } \\
\text { tency }\end{array}$ & $\begin{array}{l}\text { high af- } \\
\text { fected- } \\
\text { ness }\end{array}$ & $\begin{array}{l}\text { individu- } \\
\text { ation of } \\
\text { object }\end{array}$ & others \\
\hline CREATING & + & + & \pm & + & + & + & + & - \\
\hline TAKING UP & + & $?$ & \pm & + & $(+)$ & - & \pm & - \\
\hline COMBINING & + & + & $\mathrm{x}$ & + & + & $(+)$ & \pm & - \\
\hline COLLECTING & + & $?$ & $?$ & + & $(+)$ & - & + & - \\
\hline FINDING & $?$ & - & - & - & - & - & + & - \\
\hline $\begin{array}{l}\text { HOLD- } \\
\text { ING/STORING }\end{array}$ & + & + & + & + & - & - & + & $?$ \\
\hline PROCESSING & + & $(+)$ & + & + & + & + & \pm & - \\
\hline RECEIVING & $?$ & - & - & - & - & - & + & $?$ \\
\hline $\begin{array}{l}\text { TRANSPORT- } \\
\text { ING }\end{array}$ & + & + & + & $?$ & - & - & + & $?$ \\
\hline STH FORMS & - & $?$ & + & - & - & + & + & - \\
\hline
\end{tabular}

\subsubsection{Moving in and out}

There were two groups of conceptual metaphors that centered around locomotion, mostly of the reading person. We grouped these metaphors into two systems because in some of them, the locomotion goes into something or out of it whereas the second one lacks this distinct moment of in-out.

Most, though not all moving metaphors are an action, and in most cases, this action is telic (for an overview, see Table 2). Volitionality, though, varies across the texts - in some cases, the actor seems to be induced by an external cause to move, for instance when LEAVING the everyday world, SINKING, or SINKING ONESELF INTO a book. Also conspicuously, most of the actions are punctual or short, even if their effects are long-lasting, as in PLUNGING.

None of the metaphors has a direct object that is acted upon or handled; what is affected is the actor, not an object. Conceptually, the moving metaphors often go along with the idea of a world or space and different locations. Conspicuously again, other persons are absent, even though often a world is mentioned. Overall, thus, transitivity is rather weak in this group. 
This group contains the most frequent metaphor in our material in which reading is compared to PLUNGING INTO A DIFFERENT WORLD. It is a common expression for reading in German ("in etwas eintauchen"), but it is nevertheless striking that it is also used that frequently in the context of academic reading. A typical example is: "Reading is like plunging in another world or situation" (124).

PLUNGING is a volitional, telic and punctual action. There is only one participant. Her or his potency remains indistinct: the only action mentioned is that one enters (a punctual act), and there is no affectedness of an object - if one wants to regard the world as an object. It is difficult to decide whether the world is individuated because conceptually it indicates "everything". The actor, however, seems to be affected - the conceptual metaphor implies a shift in mode of existence. Transitivity of this conceptual metaphor is similar to ENTERING (see below in the Appendix). The main difference and the reason that we did not combine these metaphors into a single one is that plunging means immersing oneself completely into something. Although water was rarely mentioned in the texts, the German word used in all examples, "tauchen" or "eintauchen", implies a liquid that surrounds the actor. Therefore, the shift in existence mode is rather strong. This metaphor has a distinct spatiality in the sense that the person enters into a world. This world is usually not described in any detail, it is simply a container filled with undefined things.

Table 2

Moving in and out metaphors and their transitivity aspects. The sign "+" denotes the presence of an aspect, "-" its absence. A question mark indicates that the feature is unclear, " \pm " signals that the feature differed in the texts. If a sign is put into brackets, the feature is present, but not strongly so and may be of limited value for characterizing the metaphor

\begin{tabular}{|l|l|l|l|l|l|l|l|l|}
\hline & action & telic & $\begin{array}{l}\text { temp. ex- } \\
\text { tended }\end{array}$ & volitional & $\begin{array}{l}\text { high po- } \\
\text { tency }\end{array}$ & $\begin{array}{l}\text { high af- } \\
\text { fected- } \\
\text { ness }\end{array}$ & $\begin{array}{l}\text { individu- } \\
\text { ation of } \\
\text { object }\end{array}$ & \begin{tabular}{l} 
others \\
\hline PLUNGING
\end{tabular} \\
\hline ESCAPING & + & + & - & + & - & - & - & - \\
\hline BEING IN STH & \pm & $(+)$ & + & $(+)$ & - & - & - & + \\
\hline $\begin{array}{l}\text { PUTTING ONE- } \\
\text { SELF INTO }\end{array}$ & + & + & - & + & + & - & - & - \\
\hline LEAVING & + & + & - & $(+)$ & + & - & - & - \\
\hline $\begin{array}{l}\text { SINKING ONE- } \\
\text { SELF INTO }\end{array}$ & + & + & $?$ & $(+)$ & - & - & - & - \\
\hline SINKING & - & - & + & - & - & - & - & - \\
\hline ENTERING & + & + & - & + & + & - & - & - \\
\hline
\end{tabular}

\subsubsection{Moving around}

As mentioned above, this category is the second locomotion category. One prominent difference is that moving around does not imply a movement into or out of a location or space. However, the conceptual metaphors assigned to this category also implied a somewhat higher transitivity than those of the moving in and out group (see Table 3). Many, but not all conceptual metaphors imply an action. This action often is telic and volitional, but several cases lack both features such as if one inadvertently meets something or is being led by something. The action is typically extended in time. Objects are mostly absent and thus not affected. In contrast to the moving in and out group, there is also less affectedness of the person in this group. Others are absent from the metaphor; even in being led, which implies somebody or something that leads, this other is never an author but rather the story.

Overall, this is also a group of medium transitivity. Furthermore, there is considerable variability between conceptual metaphors: The action can be highly transitive (as in the case of EXPLORING) or passive/low in agency (as in the case of BEING LED or BEING MOVED). 
The most frequent metaphor in this group is TRAVELING. An example is: "a journey in my imagination. [...] You can visit fantastic worlds, relive their adventures with historical people or acquire new knowledge" (71). This is a common metaphor with a single lexical expression (German noun "Reise" or, rarely, the verb "reisen"). The activity is usually of high kinesis and volitional. Its telos is not clearly present. It is temporarily extended, that is it takes a long time. Usually, there is no object mentioned ("reisen" is intransitive), but other (rare) expressions such as "visiting something" could mention such an object. Although traveling might include several participants, others were never mentioned in our material. Traveling may imply a change in the actor. (In the example above, this is expressed by a different conceptual metaphor, ACQUIRING). Transitivity is medium. In TRAVELING, there is spatiality in the sense of a large, but rather indistinct area and a path, whenever a journey in the sense of a distinct trail is alluded to.

Table 3

Moving around metaphors and their transitivity aspects. The sign "+" denotes the presence of an aspect and "-" its absence. A question mark indicates that the feature is unclear, " \pm " signals that the feature differed in the texts. If a sign is put into brackets, the feature is present, but not strongly so and may be of limited value for characterizing the metaphor

\begin{tabular}{|c|c|c|c|c|c|c|c|c|}
\hline & action & telic & $\begin{array}{l}\text { temp. ex- } \\
\text { tended }\end{array}$ & volitional & $\begin{array}{l}\text { high po- } \\
\text { tency }\end{array}$ & $\begin{array}{l}\text { high af- } \\
\text { fected- } \\
\text { ness }\end{array}$ & $\begin{array}{l}\text { individu- } \\
\text { ation of } \\
\text { object }\end{array}$ & others \\
\hline TRAVELLING & + & \pm & + & + & + & - & \pm & - \\
\hline EXPLORING & + & + & + & + & + & - & $(+)$ & - \\
\hline MEETING & - & - & - & $?$ & - & - & + & - \\
\hline $\begin{array}{l}\text { MOVING } \\
\text { AROUND }\end{array}$ & + & \pm & + & + & + & - & - & - \\
\hline FOLLOWING & + & \pm & + & $(-)$ & $(-)$ & - & $(+)$ & - \\
\hline BEING LED & - & - & + & - & - & - & $(+)$ & - \\
\hline BACKING AWAY & + & + & \pm & + & + & - & + & - \\
\hline RECEDING & - & - & + & - & - & - & + & - \\
\hline BEING MOVED & - & - & \pm & - & - & - & - & - \\
\hline MOVING & + & - & + & - & + & - & - & - \\
\hline
\end{tabular}

\subsubsection{Being acted upon}

These metaphors do not necessarily differ in conceptual content from metaphors in other groups; the difference is rather in who is active and who is been acted upon. In all cases, what was highlighted was that the reader is influenced or forced by reading, i.e. presented as the object of an action. In most cases, the utterances used the passive voice so that the agent of the action was masked. Looking from the perspective of the reader-as-agent, these metaphors thus are of very low transitivity (see Table 4).

To give an example, the most frequent metaphor in this group was BEING INFLUENCED OR STIMULATED. A typical example is: "Reading stimulates imagination" (8). This is a rather pale metaphor and in many cases it came with the conventional expression - as in the example above - that imagination is stimulated. Agency is exceptionally low, and the reader is presented as someone to whom something happens. The source of the influence was either a book or the act of reading. 
Table 4

Metaphors of being acted upon and their transitivity aspects. The sign "+" denotes the presence of an aspect, "-" its absence. A question mark indicates that the feature is unclear, " \pm " signals that the feature differed in the texts. If a sign is put into brackets, the feature is present, but not strongly so and may be of limited value for characterizing the metaphor

\begin{tabular}{|c|c|c|c|c|c|c|c|c|}
\hline & action & telic & $\begin{array}{l}\text { temp. ex- } \\
\text { tended }\end{array}$ & $\begin{array}{l}\text { 36oli- } \\
\text { tion-nal }\end{array}$ & $\begin{array}{l}\text { high po- } \\
\text { tency }\end{array}$ & $\begin{array}{l}\text { high af- } \\
\text { fected- } \\
\text { ness }\end{array}$ & $\begin{array}{l}\text { individu- } \\
\text { ation of } \\
\text { object }\end{array}$ & others \\
\hline $\begin{array}{l}\text { BEING INFLU- } \\
\text { ENCED/ STIMU- } \\
\text { LATED }\end{array}$ & - & - & + & - & - & - & - & - \\
\hline STH AWAITS ME & - & - & + & - & - & - & - & - \\
\hline $\begin{array}{l}\text { BEING EN- } \\
\text { CHAINED }\end{array}$ & - & - & + & - & - & - & - & - \\
\hline $\begin{array}{l}\text { BEING CON- } \\
\text { FRONTED WITH }\end{array}$ & - & - & $(-)$ & - & - & - & - & - \\
\hline BEING FORCED & - & - & + & - & - & - & - & - \\
\hline
\end{tabular}

\subsubsection{Seeing and opening}

These metaphors (see Table 5) are grouped together because in Western cultures, seeing is a common metaphor for knowledge and insight, and this conceptual content is invoked by all of them. Most of them involve a weakly agentive action of (visual) perception in which there is an actor and an object, but the two do not have a direct contact (as in the handling things group). Although OPENING has only an indirect connection to seeing, it is grouped here because it renders things visible.

The action can be telic, volitional and temporally extended, but need not be so if, for instance, somebody suddenly and unwittingly discovers something. A further remarkable feature is that the object of the action is usually not affected by this action; one exception is IMAGINING in which the objects comes into being. Other persons are again absent from the conceptual metaphors, even though the existence of different perspectives may imply them.

The most frequent conceptual metaphor in this group was SEEING. An example is: "watching movies, only it's all in your head. By reading novels or other books, for example, images are constructed in the head/brain of each person that match what they have read" (53). SEEING has a spatiality characterized by distance. In our material, SEEING was usually presented as something that happens and thus is of low kinesis (there were no instances of observing or scrutinizing which would be more active). It is usually not described as strongly telic or volitional. Although seeing can be punctual, many of the examples in our material were extended in time, for instance when reading was compared to watching a movie - as in the example above. The object can be individuated or not, but it is not affected by being seen. In our material, objects of seeing were images or films rather than things. Some instances depicted the head as a container of images. Overall, thus, this conceptual metaphor has a low transitivity. 


\section{Table 5}

Seeing and opening metaphors and their transitivity aspects. The sign "+" denotes the presence of an aspect, "-" its absence. A question mark indicates that the feature is unclear, " \pm " signals that the feature differed in the texts. If a sign is put into brackets, the feature is present, but not strongly so and may be of limited value for characterizing the metaphor

\begin{tabular}{|c|c|c|c|c|c|c|c|c|}
\hline & action & telic & $\begin{array}{l}\text { temp. ex- } \\
\text { tended }\end{array}$ & $\begin{array}{l}\text { volitio- } \\
\text { nal }\end{array}$ & $\begin{array}{l}\text { high po- } \\
\text { tency }\end{array}$ & $\begin{array}{l}\text { high af- } \\
\text { fected- } \\
\text { ness }\end{array}$ & $\begin{array}{l}\text { individu- } \\
\text { ation of } \\
\text { object }\end{array}$ & others \\
\hline SEEING & - & - & \pm & $?$ & - & - & + & - \\
\hline IMAGINING & $(+)$ & + & + & + & + & + & $(+)$ & - \\
\hline $\begin{array}{l}\text { TAKING } \\
\text { PERSPEC- } \\
\text { TIVE }\end{array}$ & $(+)$ & + & + & + & $(+)$ & - & $(+)$ & $(+)$ \\
\hline $\begin{array}{l}\text { BLINDING } \\
\text { OUT }\end{array}$ & + & + & + & + & + & - & + & - \\
\hline $\begin{array}{l}\text { DISCOVER- } \\
\text { ING }\end{array}$ & - & - & - & - & - & - & $(+)$ & - \\
\hline OPENING & + & $?$ & - & + & $(+)$ & $(+)$ & $(+)$ & - \\
\hline
\end{tabular}

\subsubsection{Other Metaphors}

There were a few distinct conceptual metaphors that did not fit into any of the five groups mentioned above. They are listed in Table 6 and again explained in Appendix A. Except for BROADENING, all of them were rare in the present material. Of course, it is not possible to describe these conceptual metaphors as a whole, neither in conceptual content nor in transitivity. Overall, they match the impression gained from the further metaphors: transitivity varies, but is often low to medium and rarely high.

The most frequent conceptual metaphor in this group was BROADENING. An example is: "By reading you personally develop and broaden your horizon"(87). BROADENING has a distinct spatiality. Transitivity is interesting because approximately half of the cases in our sample came with an active voice (see the example), the other half in the passive form (one's knowledge is broadened). Therefore, kinesis, potency, volitionality and aspect are unclear and marked as variable in the table. Furthermore, BROADENING was always used in a cognitive sense (i.e. for broadening knowledge or horizon) and thus could also have been categorized as a cognitive metaphor. Lexically, however, it is more concrete than the cognitive metaphors.

Note however, that BROADENING is a common expression in German, as are SHUTTING OFF, which underlines the relaxing function of reading, and BEING SOMEONE ELSE in the sense of being one of the persons in a text. Three conceptual metaphors focus on freedom (FREEING, BEING FREE AND LETTING/LETTING GO), three others on work and exertion (WORKING, GRAPPLING AND EXERTING ONESELF). One single metaphor, SPEAKING, stresses the existence of others, though these were not mentioned in the texts. 
Table 6

Other metaphors and their transitivity aspects. The sign "+” denotes the presence of an aspect, "-” its absence. A question mark indicates that the feature is unclear, " \pm " signals that the feature differed in the texts. If a sign is put into brackets, the feature is present, but not strongly so and may be of limited value for characterizing the metaphor

\begin{tabular}{|l|l|l|l|l|l|l|l|l|}
\hline & action & telic & $\begin{array}{l}\text { temp. ex- } \\
\text { tended }\end{array}$ & $\begin{array}{l}\text { volitio- } \\
\text { nal }\end{array}$ & $\begin{array}{l}\text { high po- } \\
\text { tency }\end{array}$ & $\begin{array}{l}\text { high af- } \\
\text { fected- } \\
\text { ness }\end{array}$ & $\begin{array}{l}\text { individu- } \\
\text { ation of } \\
\text { object }\end{array}$ & others \\
\hline $\begin{array}{l}\text { BROADEN- } \\
\text { ING }\end{array}$ & \pm & \pm & \pm & \pm & \pm & + & + & - \\
\hline $\begin{array}{l}\text { SHUTTING } \\
\text { OFF }\end{array}$ & + & $(+)$ & - & + & $(+)$ & - & - & - \\
\hline FREEING & $( \pm)$ & - & - & - & $(-)$ & - & - & - \\
\hline BEING FREE & - & - & - & - & - & - & - & - \\
\hline $\begin{array}{l}\text { LETTING, } \\
\text { LETTING GO }\end{array}$ & $(-)$ & - & - & $(+)$ & - & - & - & - \\
\hline WORKING & + & - & + & + & + & - & - & - \\
\hline GRAPPLING & + & + & + & + & + & - & $(+)$ & - \\
\hline $\begin{array}{l}\text { DECIPHER- } \\
\text { ING }\end{array}$ & + & + & + & + & + & - & + & - \\
\hline $\begin{array}{l}\text { EXERTING } \\
\text { ONESELF }\end{array}$ & + & - & + & - & $(+)$ & $(+)$ & - & - \\
\hline $\begin{array}{l}\text { BEING S.O. } \\
\text { ELSE }\end{array}$ & - & \pm & + & + & $(+)$ & + & $(+)$ & + \\
\hline SPEAKING & + & + & + & + & - & - & - & + \\
\hline
\end{tabular}

\subsubsection{Cognitive processes and emotion-centered metaphors}

Perhaps not surprisingly in the academic context, a variety of the texts clustered around cognitive processes. These are not conceptual metaphors in the strict sense, because they usually are as abstract as the concept to be explained by them. Because these expressions were so common, we want to report them, well aware that they are analogies rather than metaphors. The same arguments can be put forward for a group of emotion-centered descriptions to which we want to draw attention because most of them have emotional content - which is conspicuously absent from almost all of the other metaphors.

The cognitive analogies are LISTENING, PERCEIVING, LEARNING, FORGETTING, FOCUSING, QUESTIONING and EXPERIENCING, the emotional analogies are RELAXING/ENJOYING/FINDING COMFORT, VACATION and EMPATHIZING WITH OTHERS. A few texts compared reading explicitly to a negative experience such as stepping barefoot on a lego brick.

The emotional analogies are low in transitivity (the effects being on the side of the participants whose agency is low), the cognitive analogies have mixed transitivity, varying from very low in forgetting or dreaming over medium in listening, perceiving and experiencing to reasonably high in questioning and grappling.

\subsection{Quantitative results}

The 139 texts ( 4 descriptions were missing, possibly because the students overlooked the page with "reading is like ...") were coded by two independent coders one of whom was partly and the other not at all 
involved in the development of the codes. Each identified close to 500 conceptual metaphors (MK: 490 codings, SB: 477 codings), ranging from zero to eleven metaphors per text. Interrater agreement for the 66 categories was 82.42, resulting in interrater reliability or Cohen's $\kappa=.84$ (Cohen, 1960) which can be regarded as excellent agreement (Fleiss \& Cohen, 1973; Wirtz \& Caspar, 2002).

Figure 1 gives an overview of the frequency of the different groups. Conceptual metaphors of locomotion are the most common. They account for roughly 30\% of all codings. Seeing/opening and handling things metaphors each cover about $14 \%$. Metaphors which put into focus that the person is being acted upon are comparably rare.

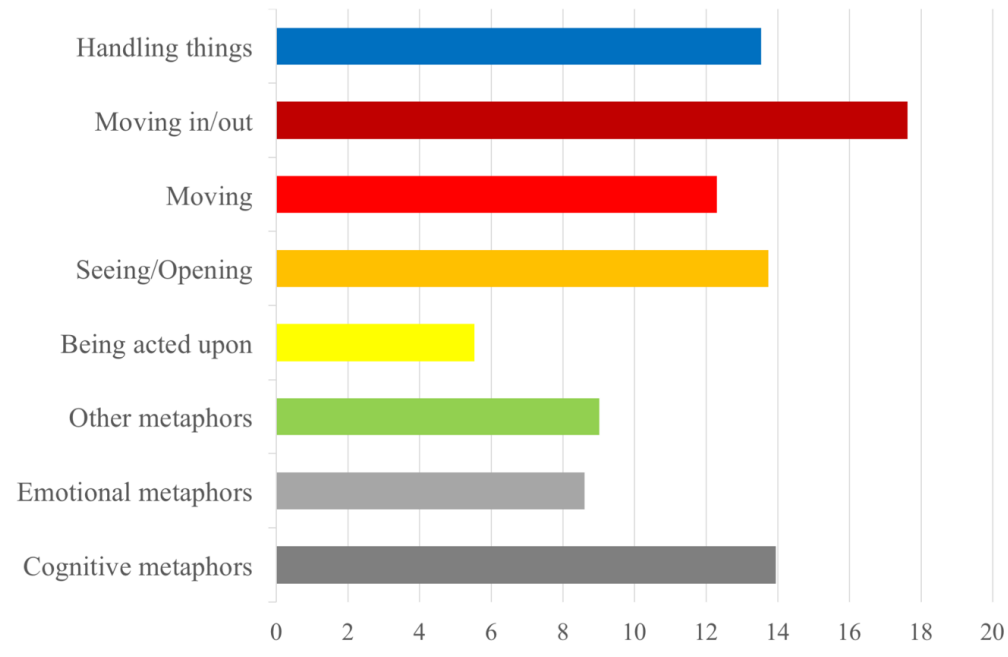

Figure 1: Percentages of codings in the different groups.

Within the groups, there is a very unequal distribution of codings. Very few metaphors are used widely; many others are very rare. Table 7 gives the frequencies of all categories and Figure 2 depicts the percentages of codings for those conceptual metaphors that had at least 10 codings.

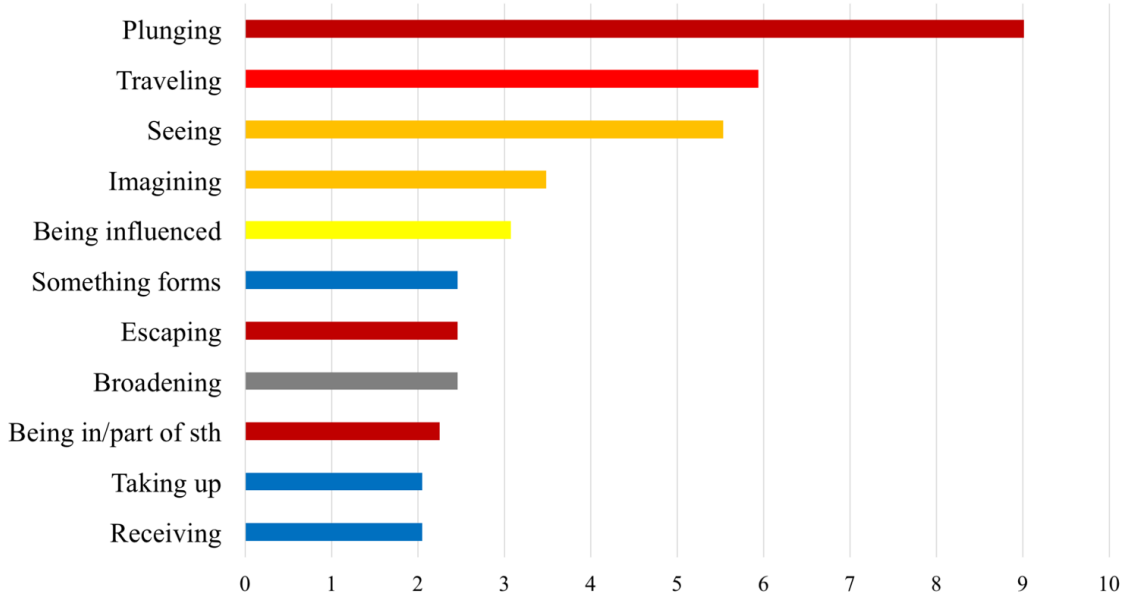

Figure 2: Percentages of codings for the more frequent metaphors. Colors as in Figure 1. 
The three most frequent metaphors are PLUNGING, TRAVELING and SEEING, followed by IMAGINING and BEING INFLUENCED. These metaphors are conceptually very different. PLUNGING and TRAVELING draw on a change of location, one punctual, the other one temporally extended. PLUNGING implies that reading is something that a person only has to kick off. This is fairly similar in ESCAPING, although the activity here is somewhat longer and has more 'force'. SEEING puts the activity of perception into focus. IMAGINING is similar because most texts in which this metaphor was found focused on imagining visual material, but it implies higher transitivity. BEING INFLUENCED is an internally variable category in which the reader is depicted as passive and suffers from what is happening. STH FORMS implies the emergence of an object independent of the reading person, TAKING UP and RECEIVING the transfer of an object from one location to another. BROADENING and BEING IN/PART OF STH underline changes in the reading person, though of different kinds. Yet, the metaphors are similar in that all are at most medium in transitivity. Except for IMAGINING and STH FORMS, none of the metaphors implies an effect on the object. With the exception of the same two conceptual metaphors, all metaphors imply an effect on the actor that may be weak and reversible as in SEEING and RECEIVING, but also strong as in ESCAPING. Most of the metaphors have low aspect (as in RECEIVING) or low volitionality (as in ESCAPING) or neither (as in FORGETTING). The only frequent conceptual metaphors that depict readers as effective and active agent are IMAGINING and TRAVELING. In both cases, however, there is no effect of this agent on the world.

Table 7

Conceptual metaphors of reading together with their frequency

\begin{tabular}{|c|c|c|c|}
\hline Handling things & Moving in or out & Moving around & Seeing and opening \\
\hline TAKING UP/INCORPO- & SINKING (3) & FOLLOWING (2) & SEEING (27) \\
\hline RATING (10) & ENTERING (2) & MOVING AROUND (1) & IMAGINING (17) \\
\hline CREATING (8) & PLUNGING (44) & TRAVELLING (29) & TAKING PERSPECTIVES \\
\hline HOLDING/STORING (3) & PUTTING ONESELF & EXPLORING (8) & (9) \\
\hline COLLECTING (4) & INTO (6) & BACKING AWAY (1) & BLINDING OUT (3) \\
\hline TRANSPORTING (6) & LEAVING (4) & RECEDING (2) & DISCOVERING (6) \\
\hline PROCESSING (2) & SINKING ONESELF INTO & MEETING (2) & OPENING (4) \\
\hline COMBINING (7) & (4) & BEING LED (2) & \\
\hline FINDING (4) & ESCAPING (12) & BEING MOVED (7) & \\
\hline $\begin{array}{l}\text { RECEIVING (10) } \\
\text { STH FORMS (12) }\end{array}$ & BEING IN STH (11) & MOVING (6) & \\
\hline Being acted upon & Further Metaphors & $\begin{array}{l}\text { Emotion-centered } \\
\text { metaphors }\end{array}$ & Cognitive metaphors \\
\hline STH AWAITS ME (5) & FREEING (3) & RELAXING, ENJOYING, & LISTENING (2) \\
\hline BEING CONFRONTED & BEING FREE (3) & FINDING COMFORT & PERCEIVING (6) \\
\hline WITH (3) & LETTING GO (5) & $(18)$ & DREAMING (10) \\
\hline BEING FORCED (1) & WORKING (3) & VACATION (8) & LEARNING (18) \\
\hline BEING ENCHAINED (3) & GRAPPLING (2) & EMPATHIZING (4) & FORGETTING (12) \\
\hline \multirow{7}{*}{$\begin{array}{l}\text { BEING INFLUENCED } \\
\text { (15) }\end{array}$} & DECIPHERING (1) & BEING SOMEONE ELSE & FOCUSING (9) \\
\hline & EXERTING ONESELF (3) & (4) & QUESTIONING (1) \\
\hline & IMPROVING (2) & NEGATIVE EXPERI- & EXPERIENCING (10) \\
\hline & BROADENING (12) & ENCES (8) & \\
\hline & SHUTTING OFF (7) & & \\
\hline & CHOOSING & & \\
\hline & SPEAKING & & \\
\hline
\end{tabular}




\section{Discussion}

Focusing on metaphors, the present study addressed one aspect of individual understanding of academic reading. In contrast to earlier studies (Paulson \& Armstrong, 2011; Paulson \& Theado, 2015; for studies on other academic practices see Saban, Kocbeker \& Saban, 2007; Wegner \& Nückles, 2015a, 2015b, 2016), we identified a large variety of conceptual metaphors. Although we could cluster them into a few discernable groups, there is considerable intra-group variability, especially if one takes transitivity, that is, the amount of agency and impact, into account.

This main finding agrees well with a study by Paulson and Armstrong (2011) who analyzed the reading and writing metaphors of college students enrolled in developmental reading and writing classes. They classified the metaphors according to negative/nonnegative responses and with respect to literacy as a process vs. literacy as a product. Negatively connoted metaphors were rare (approximately on sixth of the metaphors) and product metaphors were almost three times as frequent as process metaphors. Furthermore, Paulson and Armstrong semantically analyzed the metaphorical expressions and identified several different conceptual metaphors, among them COLLEGE READING IS A JOURNEY, COLLEGE READING IS A SPORT, COLLEGE WRITING IS A GAMING ACTIVITY, and COLLEGE WRITING IS FREEDOM OF EXPRESSION. Overall, the authors underline the variability of conceptualizations. Somewhat surprisingly they do not directly target the variability and report only very few conceptual metaphors. This gap is filled by the present study.

However, we also identified some rather common features. Leaving the emotional and cognitive metaphors aside, students' conceptualizations mainly drew on the concrete actions of handling things, of locomotion or being moved and of seeing and opening. One further group centered around different experiences of being acted upon.

Although transitivity or the amount of agency in our metaphors varied from extraordinarily low to very high, many metaphors were at most medium in transitivity. The most frequent aspects of low transitivity were the absence of other persons, who were rarely mentioned or implied by the conceptual content, the absence of individuated objects and a frequent lack of affectedness of the object. What is more, the reading person was often depicted as affected (strictly linguistically speaking as the object of a rather transitive action by someone or something else). Reading repeatedly appeared as a passive uptake of information - a notion that has been characterized as an intuitive everyday notion of reading (Christmann \& Groeben, 1999, p. 145) -, but more often as being affected rather than affecting or acting.

This overall picture contrasts with psychological theories of reading (e.g. Christmann \& Groeben, 1999; Schaffner, 2009) and educational approaches to supporting academic reading (e.g. Bean, Chappell \& Gillam, 2014). According to current models of reading (e.g., Kintsch, 1987; Kintsch \& van Dijk, 1978), text comprehension is an active and complex process of meaning-making, that is, an interaction between information in the text and reader knowledge or expectations (even though some reading processes may be regarded as passive resulting in differences in the amount to which readers are seen as active, Cook \& O'Brien, 2019). This interaction is regulated by the reader. Such regulation does not necessarily imply conscious control, but it does imply activity, a flexible, cognitive and constructive interaction.

Furthermore, different processes are involved in reading, some more bottom-up (that is influenced by the text, for instance its coherence), others more top-down (influenced by the reader's knowledge, goals or expectations). Extraction of meaning, for instance, can be studied at the levels of words, word combinations and sentences as well as the meanings of whole texts. Also, reading does not only involve cognitive processes of understanding, but also attention, emotion, motivation and self-regulation of these processes.

In terms of the transitivity aspects defined by Hopper and Thompson (1980), according to cognitive or psychological theories reading has to be seen as an action, consisting of several different activities that have to be controlled and coordinated. It is temporally extended and - taking meaning as its object - has a highly individuated object which is strongly affected by reading. Although reading may be automatic, reading of academic texts will be only weakly automatic but rather telic and volitional with a reader who is high in potency. This is almost the opposite of what we found in the concepts of the students. 
The same striking contrast between students' metaphors and scholarly conceptualizations holds true for sociocultural theories of reading. According to Ridley (2004), encounters and struggles with academic reading practices belong to crucial literacy and learning experiences for students. In the sociocultural literature on academic literacy, reading is often treated much less explicitly than writing. Some of the conceptions related to reading from a sociocultural perspective have thus to be inferred from the respective understanding of writing, which is presented in a more straightforward fashion. Perhaps this has to do with the fact that sociocultural theories view writing as the participation in social discourse(s), which already implies a to-and-fro-movement between the various interacting persons as readers-and-writers.

It is exactly this interactive view of discourse that is most characteristic for sociocultural conceptualizations, be they explicitly or only implicitly focused on reading. The Vygotskian notion of sociogenesis of higher mental functions and the Brunerian concept of scaffolding in language learning are at the core of a sociocultural understanding of reading (Langer \& Applebee, 1986). From this perspective, interaction with adults and "more capable peers" (Vygotsky, in Cole et al., 1978) is central to grow into the reading practices of a given society and even of particular groups within that society. Through legitimate peripheral participation learners become part of their communities (Lave, 1991; Lave \& Wenger, 1991) - with regard to academic reading, this is the interaction in class (with faculty and peer students) and in informal peer settings (Havnes, 2008). We would expect students to mirror the interactive nature of reading and learning to read in their metaphors, e.g. by depicting the reader as social agent who is in connection to other persons. Contrasting more cognitive concepts of reading, from a sociocultural stance readers can be conceptualized both as agentive and as patientive actors, i.e. rather as acting on others (e.g. talking to persons, discussing, arguing or even fighting with them) or as being acted upon (e.g. being guided). In this line of argument, social status and power relations are seen to be crucial to academic literacies (Lea \& Street, 2006; Lillis, 2003; Lillis \& Scott, 2007). We would thus expect them to feature in students' metaphors and especially in their transitivity status.

Another characteristic of reading from a sociocultural perspective is that it draws not on language in general but on a variety of social languages, depending on which socially situated discourses the reading activity is part of (Gee, 2013). In the realm of academic reading and writing, this fact is most attended to in genre theories (Swales, 1990; for an overview of sociocultural studies, see Russell, 1997). We would expect students to mirror this fact by providing a differentiated use of metaphors and by distinguishing between metaphors for reading in a variety of genres and social settings. However, we could not find such pondering over the adequacy of metaphors for different types of texts and functions of reading in our material. We have to note, however, that our questions "Reading is like ..." did not ask for such a differentiation.

Why is it the case that most metaphors that the students in our sample produced are rather different from or even stand in contrast to the main points of scientific theories of reading?

The following answers to this question are speculative in the sense that they only address possible reasons. Therefore, they should be regarded as questions for further research. One possibility is that students produced everyday notions of reading based on common expressions for reading in their everyday language. As mentioned above, "plunging into" is not too uncommon an expression associated with reading in the German language. Such everyday notions can, as research on preconceptions and subjective theories has shown, differ clearly from academic concepts and may exist in addition to them, even if they contradict one another. Another possibility is that the students addressed leisurely reading instead of reading of academic texts. Assuming that leisurely reading is less active than reading of scientific texts, the difference might then be due to two different concepts. Note however that this pertains more to the subjective experience of reading than to the processes driving it; these are the same and similarly constructive, although somewhat less effort or regulation of motivation may be necessary for leisurely reading. A third possibility is that many of the processes involved in reading, including the constructive ones, may be intransparent to the reader. Once automated, routines such as moving the eyes towards relevant words and leaving out predictable ones or reading more slowly when working through difficult and dense parts of texts may be so inconspicuous that the reader does not recognize their constructive nature. One further interesting idea (we are thankful to a reviewer who pointed this possibility out) is that metaphors may capture aspects of reading that are not that easily observed within scientific models of reading. Modern empirical psychology, successful as it is, is rather suspicious of subjective, phenomenological or introspective, approaches to practices such as reading. Seeing reading as, for in- 
stance, plunging or seeing might capture interesting dimensions of reading, for instance the phenomenal experience that the content is there (in seeing) and that context changes a person (as in plunging); the individual might even be much less autonomous than psychological thinking claims. Note, however, that the disagreement to scientific theories is as strong in the case of psychological models as in that of sociocultural approaches which aim to be more true to actual experience. Our present material was not intended to identify the causes of the discrepancy between metaphorical concepts and scientific theories of reading, but it reveals this discrepancy as a fascinating area for further research.

To turn to possible practical consequences of our study, academic reading and writing are difficult problems for undergraduates, and it appears that even if universities seek to support the students, these problems are rather persistent. The results of the present study indicate one reason for these difficulties: Students' conceptualizations of reading may differ strongly from how staff or researchers understand such practices. Besides pointing out this problem, the present study also indicates possible lines of action.

Metaphors can be understood as a variant of analogical reasoning, in which representations/their structures, one better and one less understood, are aligned (e.g., Gentner, 1983, 2010). Analogical reasoning in turn can be used for scaffolding understanding of complex issues such as scientific phenomena - or academic practices such as thinking, writing or reading. For this, one would have to identify the structures of the source domain - for instance the lexical and grammatical aspects ${ }^{3}$ described in the results section - and compare them to academic reading in order to find out which elements match and which match less or not at all.

Such an approach does not imply that there is a correct metaphor of academic reading. Sfard (1998), for instance, pointed out that the ACQUISITION metaphor for learning (such as in LEARNING IS EATING) is often considered a simple and insufficient metaphor, inferior to, for instance, ENCULTURATION Or PARTICIPATION metaphors (as in LEARNING IS GROWING or LEARNING IS BECOMING PART OF SOMETHING). However, she explicitly warned against such a simplification. Metaphors establish perspectives and thus help to look at things in related and necessary, but disparate and maybe even not reconcilable ways. For instance, the seemingly simple ACQUISITION metaphor helps to understand individual change or transfer and transfer problems better than the apparently more complex PARTICIPATION metaphor.

The same could be argued with respect to the reading metaphors. If we take only the most frequent ones, PLUNGING could be seen as simplistic: It implies that reading has only to be kicked off, what is done is only one punctual step; afterwards, no activity is necessary. This does not capture the activity and self-regulation that are necessary for constructing meaning from scientific texts, especially if one is very new to a field or domain, but it accords better with more expert reading in which the process of meaning construction requires little effort and, taking this perspective, is not simplistic. To give another example, the TRAVELING metaphor highlights that reading may change the person and involve a change of location or context. Again, this reveals aspects typical of academic reading - for instance that it is an activity with a long temporal perspective and a practice that is typical for special educational settings at universities and different form 'ordinary life', but may not be easily transferable to other communities. On the other hand, it tends to hide the necessary effort on the side of the reader. SEEING, finally, hides the reader's activity as well as the fact that meaning is negotiated and not something that is simply there, but it may single out the distance that is helpful in understanding academic texts.

Departing from transitivity analysis and in accordance with Paulson and Armstrong's claim that ,classroom conversations need to directly address [student] conceptualizations of academic literacies“ (2011, p. 501), researchers could work actively with and on metaphors that are typically used by students as well as staff. Note that we do not recommend directly changing student metaphors. Drawing on the understanding that all metaphors highlight some aspects and hide others (Lakoff and Johnson, 2003) and that academic practices are too complex, variable and negotiated to be understood in a single perspective (Sfard, 1998) we suggest to focus on addressing or changing some of their aspects, especially certain transitivity features. For instance, SEEING has very low transitivity. One may see something involuntarily, in just a moment and without effort features that would be incongruent with academic reading. This match would be, however, improved if one

\footnotetext{
${ }^{3}$ One could also think of further structural elements such as spatiality which, among others, Lakoff and Johnson (2003) described as an important aspect of metaphors.
} 
moved from SEEING to IMAGINING, in which the person creates the imagined content, or OBSERVING, which implies more activity that is furthermore extended in time. Both SEEING and OBSERVING stress that reading has to be true to the text whereas IMAGINING underlines the constructive activity of the reader. Together, these metaphors may illustrate the interplay of bottom-up and top-down processes in reading as well as different and contradictory demands on the reader. Turning to PLUNGING, this metaphor may be used to underline the difference between academic and everyday reading. However, the impression of being immersed into something can also be true of academic reading, and even though reading is an active and constructive process, it also has an element of immersion that cannot be produced, but only be set off by the reader. To underline the temporal extension and recursiveness of reading as well as effort and agency, the PLUNGING metaphor could be turned into a DIVING metaphor. Turning to the third of the three most frequent metaphors, TRAVELING, it may be used to underline the existence of different discourse communities as well as the fact that students switch back and forth between different discourse communities and often do not feel completely at home in any of them - often not even as a legitimate peripheral participant (Lave \& Wenger, 1991).

Freebody and Luke (1990) stress the different roles of the reader, which are all suitable to be developed by extending and re-shaping students' metaphors. The reader as code-breaker highlights the technical, deciphering and rule-following nature of reading. This reader-role could be developed within students' metaphors that involve handling of things as well as the entrance into unknown worlds. The role of reader as text participant who infers meaning from background knowledge and constructs and connects knowledge (see the cognitive reading theories discussed above) could be strengthened if academic reading is conceptualized as active handling of things involving shaping or building metaphors common to writing (Scharlau, Rohlfing \& Karsten, subm.). This active image of the reader could be even further extended to conceptualize the reader as text user, when the metaphors imply handling of things in real-life and metaphors of the text as a tool to achieve goals in the world. The fourth reader role, the reader as text analyst, can be developed if the reader is seen to be in dialogue and interaction with other persons, involving metaphors of discourse and dialogue, discussion and argumentation (see the sociocultural reading theories discussed above). Academic reading and writing researcher Bean (2011, p. 138) reports that students enjoy playing with metaphors when grappling with topic content and has described methods to use metaphors in the classroom (see also Elbow, 1998).

In a longitudinal study, Wegner and Nückles (2015) concluded that students' metaphors of learning developed during their first year at university. Although in approximately half of their sample the students' main metaphorical content or source concept did not change, in the other half it did. Students who had used a collecting source (such as EATING) at the time of the first assessment were likely to change their metaphors. Students who had used metaphors congruent with enculturation such as a flower (GROWING) or journey (DISCOVERING) did not change their metaphors. The latter are more consistent with how universities conceptualize learning (see also Wegner \& Nückles, 2013). Such a change in the direction of more discourse-appropriate metaphors could be fostered by explicit work on metaphors. This seems even more important because a few studies have shown that metaphors of learning can influence study practices and success (Landau, Oyserman, Keefer \& Smith, 2014; Ryan, 2001; Wegner \& Nückles, 2016).

The present study is, however, only a first step towards a thorough understanding of the role of metaphors as conceptualizations of academic practices. Firstly, although the system of conceptual metaphors is large and likely to cover a large amount of metaphorical descriptions, data sampling should be expanded to graduate students and experienced academics. This is necessary to substantiate the claim that our list indeed captures the range of metaphorical conceptualizations of reading. Part of the divergence between our metaphor groups and scientific accounts of academic reading may result from the fact that we sampled metaphors only from undergraduate students. Secondly, use of metaphors may vary across groups, not only beginners and experts, but also members of different discourse communities or disciplines. Several studies have shown that reading practices are very different in different disciplines (e.g. Shanahan, Shanahan \& Misischia, 2011; Wineburg \& Reisman, 2015). It might be advisable to compare metaphors at least across different disciplines such 
as the humanities and sciences. ${ }^{4}$ And finally, metaphors may vary according to genre or text type such as reading of scientific literature, of textbooks, fiction or news or websites.

Furthermore, it is yet unclear how reading metaphors are related to other conceptualizations of reading such as conceptions, beliefs or attitudes, for instance the two reading beliefs or epistemologies reported by Schraw and Bruning (1996), one transmissional and one transactional. According to the transmissional belief, texts or authors convey meaning to readers; in the transactional belief, meaning is constructed by the interaction of readers, writers and text. The first view draws on a common metaphor that is used in many different context, CONDUIT (Reddy, 1979). Transmissional views are present in the conceptual metaphors of TAKING UP, RECEIVING, and TRANSPORTING metaphors in the present study, and although beliefs and metaphors are different cognitive constructs and stem from different theoretical backgrounds, it would be worthwhile to study the contribution of metaphorical language, thinking and discourse to such beliefs.

\section{Keypoints}

- Students used very different metaphors for describing reading, speaking to the heterogeneity of their understanding of academic reading.

- Students did not associate reading with an activity of high agency or impact.

- Students' metaphorical understanding of reading does not agree well with either cognitive or sociocultural approaches to reading.

\section{Acknowledgments}

We gratefully acknowledge the help of Sonia Kampel, Jana Schwede, and Anastasia Schulz with transcribing the students' texts and developing a precursor of the system of conceptual metaphors, and the help of Silvia Burkhardt with coding the metaphors.

\section{References}

Bean, J. C. (2011). Engaging ideas: The professor's guide to integrating writing, critical thinking, and active learning in the classroom (rev. 2nd ed.). San Francisco, CA: Jossey Bass.

Blumenberg, H. (2012). Quellen, Ströme, Eisberge [Springs, streams, icebergs]. Frankfurt am Main: Suhrkamp.

Bowden, J., \& Marton, F. (2000). The university of learning. London: Kogan Page. doi: $10.4324 / 9780203416457$

Cohen, J. (1960). A coefficient of agreement for nominal scales. Educational and Psychological Measurement, 20, 37-46. doi: 10.1177/001316446002000104

Cook, A. E., \& O'Brien, E. J. (2019). Fundamental components of reading comprehension. In J. Dunlosky \& K. A. Rawson (Eds.), The Cambridge handbook of cognition and education (pp. 237-265). Cambridge, UK: Cambridge University Press.

Christmann, U. \& Groeben, N. (1999). Psychologie des Lesens [Psychology of reading]. In B. Franzmann, K. Hasemann, D. Löffler \& E. Schön (Eds.), Handbuch Lesen [Handbook of reading] (pp. 145-223). München: Saur. doi: 10.1515/9783110961898.145

Cole, M., John-Steiner, V., Scribner S., \& Souberman, E. (Eds.) (1978). L.S. Vygotsky - Mind in society: The development of higher psychological processes. Cambridge: Harvard University Press.

\footnotetext{
${ }^{4}$ We may add that we are currently evaluating a large sample of metaphors from informatics and literature students both in early and late semesters that indicates that neither disciplinary nor time differences are large (Scharlau \& Karsten, in prep.).
} 
Elbow, P. (1998). Writing with power: Techniques for mastering the writing process. Oxford: Oxford University Press.

Evans, V. \& Green, M. (2006). Cognitive Linguistics: An introduction. Edinburgh: Edinburgh University Press.

Fleiss, J. L., \& Cohen, J. (1973). The equivalence of weighted kappa and the intraclass correlation coefficient as measures of reliability. Educational and Psychological Measurement, 33, 613-619. doi: 10.1177/001316447303300309

Freebody, P., \& Luke, A. (1990). Literacies programs: Debates and demands in cultural context. Prospect: An Australian Journal of TESOL, 5, 7-16.

Gee, J. P. (2013). Reading as situated language: A sociocognitive perspective. In D. E. Alvermann, N. J. Unrau \& R. B. Ruddell (Eds.), Theoretical models and processes of reading (6th ed.) (pp. 136-151). Newark, DE: International Reading Association. doi: 10.1598/0710.04

Gentner, D. (1983). Structure-mapping: A theoretical framework for analogy. Cognitive Science, 7, $155-170$. doi: $10.1207 / \mathrm{s} 15516709 \operatorname{cog} 0702 \_3$

Gentner, D. (2010). Bootstrapping the mind: Analogical processes and symbol systems. Cognitive Science, 34 , 752-775. doi: 10.1111/j.1551-6709.2010.01114.x

Gibbs, R. W. (1994). The poetics of mind. Cambridge: Cambridge University Press.

Gorzycki, M., Howard, P., Allen, D., Desa, G., \& Rosegard, E. (2016). An exploration of academic reading proficiency at the university level: A cross-sectional study of 848 undergraduates. Literacy Research and Instruction, 52, 142-162.

Graff, G. \& Birkenstein, C. (2014). “They say/I say”: The moves that matter in academic writing (3rd ed.). New York: Norton.

Havnes, A. (2008). Peer-mediated learning beyond the curriculum. Studies in Higher Education, 33, $193-204$. doi: 10.1080/03075070801916344

Hermida, J. (June 14, 2009). The importance of teaching academic reading skills in first-year university courses. doi: 10.2139/ssrn.1419247

Hopper, P. J., \& Thompson, S. A. (1980). Transitivity in grammar and discourse. Language, 56, 251-299. doi: $10.2307 / 413757$

Kintsch, W. (1986). Learning from text. Cognition and Instruction, 3, 87-108. doi: $10.1207 / \mathrm{s} 1532690 x \mathrm{xi0302} 1$

Kintsch, W., \& van Dijk, T. (1978). Toward a model of text comprehension and production. Psychological Review, 85, 363-394. doi: 10.1037/0033-295X.85.5.363

Kövecses, Z. (2002). Metaphor: a practical introduction. Oxford: Oxford University Press.

Kövecses, Z. (2010). A new look at metaphorical creativity in cognitive linguistics. Cognitive Linguistics, 21, 663-697. doi: 10.1515/cog1.2010.021

Krajewski, M. (2015). Lesen Schreiben Denken: Zur wissenschaftichen Abschlussarbeit in 7 Schritten [Reading writing thinking: In seven steps to a scientific thesis]. Köln: Böhlau Verlag.

Lakoff, G., \& Johnson, M. (1980). Metaphors we live by. Chicago: University of Chicago Press. doi: 10.7208/chicago/9780226470993.001.0001

Landau, M. J., Meier, B. P., \& Keefer, L. A. (2010). A metaphor-enriched social cognition. Psychological Bulletin, 136, 1045-1067. doi: 10.1037/a0020970.

Landau, M. J., Oyserman, D., Keefer, L. A., \& Smith, G. C. (2014). The college journey and academic engagement: How metaphor use enhances identity-based motivation. Journal of Personality and Social Psychology, 106, 679-698. doi: 10.1037/a0036414

Langer, J. A., \& Applebee, A. N. (1986). Reading and writing instruction: Toward a theory of teaching and learning. Review of Research in Education, 13, 171-194. doi: 10.2307/1167222

Lave, J. (1991). Situated learning in communities of practice. In L. B. Resnick, J. M. Levine \& S. D. Teasley (Eds.), Perspectives on socially shared cognition (pp. 63-82). Washington DC: APA Books. doi: 10.1037/10096-003

Lave, J., \& Wenger, E. (1991). Situated learning: Legitimate peripheral participation. Cambridge: Cambridge University Press. doi: 10.1017/CBO9780511815355

Lea, M. R., \& Street, B. V. (2006). The „Academic Literacies“ model: Theory and applications. Theory into Practice, 145, 368-377. doi: 10.1207/s15430421tip4504_11 
Lillis, T. (2003). Student writing as ,Academic Literacies': Drawing on Bakhtin to move from critique to design. Language \& Education, 17, 192-207. doi: 10.1080/09500780308666848

Lillis, T., \& Scott, M. (2007). Defining academic literacies research: Issues of epistemology, ideology and strategy. Journal of Applied Linguistics, 4, 5-32. doi: 10.1558/japl.v4i1.5

Löfström, E., Nevgi, A., Wegner, E., \& Karm, M. (2015). Images in research on teaching and learning in higher education. In J. Huisman \& M. Tight (Eds.), Theory and method in higher education research, Volume 1 (pp. 191-212). Bigley, UK: Emerald Group Publishing Limited. doi: 10.1108/S2056375220150000001009

Marton, F., \& Säljö, R. (1976). On qualitative differences in learning: I-Outcome and process. British Journal of Educational Psychology, 46, 4-11. doi: 10.1111/j.2044-8279.1976.tb02980.x

Middendorf, J., \& Shopkow, L. (2018). Overcoming student learning bottlenecks: Decode the critical thinking of your discipline. Sterling, VA: Stylus.

Pace, D. (2017). The decoding the disciplines paradigm: Seven steps to increased student learning. Bloomington IA: Indiana University Press. doi: 10.2307/j.ctt2005z1w

Paulson, E. J., \& Armstrong, S. L. (2011). Mountains and pit bulls: Students' metaphors for college transitional reading and writing. Journal of Adolescent \& Adult Literacy, 54, 494-503. doi: 10.1598/JA AL.54.7.3

Paulson, E. J., \& Theado, C. K. (2015). Location agency in the classroom: A metaphor analysis of teacher talk in a college developmental reading class. Classroom Discourse, 6, 1-19. doi: $10.1080 / 19463014.2914 .888360$

Prior, P. (2005). A sociocultural theory of writing. In C. A. MacArthur, S. Graham \& J. Fitzgerald (Eds.), The handbook of writing research (pp. 54-66). New York: Guilford Press.

Reddy, M. J. (1979). The conduit metaphor: A case of frame conflict in our language about language. In A. Ortony (Ed.), Metaphor and thought (pp. 284-310). Cambridge: Cambridge University Press. doi: 10.1017/CBO9781139173865.012

Ridley, D. (2004). Puzzling experiences in higher education: Critical moments for conversation. Studies in Higher Education, 29, 91-107. doi: 10.1080/1234567032000164895

Russell, D. R. (1997). Writing and genre in higher education and workplaces: A review of studies that use cultural-historical activity theory. Mind, Culture, and Activity, 4, 224-237. doi: $10.1207 / \mathrm{s} 15327884 \mathrm{mca} 0404 \_2$

Ryan, M. P. (2001). Conceptual models of lecture learning: Guiding metaphors and model-appropriate notetaking practices. Reading Psychology, 22, 289-312. doi: 10.1080/02702710127638

Saban, A., Kocbeker, B.N. \& Saban, A. (2007). Prospective teachers' conceptions of teaching and learning revealed through metaphor analysis. Learning and Instruction, 17, 123-139. doi: 10.1016/j.learninstruc.2007.01.003

Schaffner, E. (2009). Determinanten des Leseverstehens [Determinants of reading comprehension]. In W. Lenhard \& W. Schneider (Eds.), Diagnostik und Förderung des Leseverständnisses [Diagnostic and support of reading comprehension] (pp. 19-44). Göttingen: Hogrefe.

Scharlau, I., \& Karsten, A. (in prep.). Heterogeneity and development in undergraduates' metaphors of writing. Manuscript in preparation.

Scharlau, I., Rohlfing, K. J., \& Karsten, A. (subm.). Building, emptying out, or dreaming? Action structures and space in students' metaphors of academic writing.

Schraw, G., \& Bruning, R. (1996). Readers' implicit models of reading. Reading Research Quarterly, 31, 290305. doi: $10.1598 /$ RRQ.31.3.4

Sfard, A. (1998). On two metaphors of learning and the dangers of choosing just one. Educational Researcher, 27, 4-13. doi: 10.3102/0013189X027002004

Shanahan, T. (2015). Relationships between reading and writing development. In C. A. McArthur, S. Graham, \& J. Fitzgerald (Eds.), Handbook of writing research (2nd ed.) (pp. 194-210). New York: The Guilford Press.

Shanahan, C., Shanahan, T., \& Misischia, C. (2011). Analysis of expert readers in three disciplines: History, Mathematics, and Chemistry. Journal of Literacy Research, 43, 393-429. doi: $10.1177 / 1086296 \times 11424071$

Steen, G. (2011). The contemporary theory of metaphor - Now new and improved! Review of Cognitive Linguistics, 9, 26-64. doi: 10.1075/bct.56.03ste 
Sternberg, R. J. (2005). The psychologist's companion: A guide to scientific writing for students and researchers (4th ed.). Cambridge: Cambridge University Press.

Swales, J. M. (1990). Genre analysis: English in academic and research settings. Cambridge: Cambridge University Press.

Wegner, E., \& Nückles, M. (2013). Kompetenzerwerb oder Enkulturation? Lehrende und ihre Metaphern des Lernens [Competence achievement or enculturation? University staff and their metaphors of learning]. Zeitschrift für Hochschulentwicklung, 8, 15-29. doi: 10.3217/zfhe-8-01/04

Wegner, E., \& Nückles, M. (2015a). From eating to discovering: How metaphors of learning change during students' enculturation. Zeitschrift für Hochschulentwicklung, 10, 145-166. doi: 10.3217/zfhe-10$04 / 08$

Wegner, E., \& Nückles, M. (2015b). Knowledge acquisition or participation in communities of practice? Academics' metaphors of teaching and learning at the university. Studies in Higher Education, 38, 624643. doi: 10.1080/03075079.2013.842213

Wegner, E., \& Nückles, M. (2016). Training the brain or tending a garden? Students' metaphors of learning predict self-reported learning patterns. Frontline Learning Research, 3(4), 95-109. doi: 10.14786/flr.v3i4.212

Wineburg, S., \& Reisman, A. (2015). Disciplinary literacy in history: A toolkit for digital citizenship. Journal of Adolescent \& Adult Literacy, 58 (8), 636-639. doi: 10.1002/jaal.410

Wirtz, M., \& Caspar, F. (2002). Beurteilerübereinstimmung und Beurteilerreliabilität [Interrater agreement and interrater reliability]. Göttingen: Hogrefe. 


\section{Appendix: The conceptual metaphors}

In this appendix, the conceptual metaphors we identified in the material are described and presented with an example. The coding handbook (which is largely overlapping with the following descriptions, but contains some further instructions and is written in German) can be requested from the first author.

\section{Handling things}

\section{TAKING UP/INCORPORATING STH}

Example: "Taking up knowledge, ideas and opinions, which one could not develop by one's own effort" (92).

In this metaphor, reading is described as taking up things or elements which are then inside the person. Neither the things nor the actor are described as being strongly affected by taking up. The action is volitional, but neither strongly telic nor temporally extended. In our examples, the object was not strongly individuated - it was either "something", "information" or "knowledge".

\section{CREATING STH}

Example: "During reading, images are created in your head and you can expand and decorate them with your own imagination. If you read a book, you can create your own universe in which you can escape and escape from the stress of everyday life" (140).

By creating, things come into existence. Therefore, this conceptual metaphor has very high transitivity. Creating is volitional and telic, and it can be more or less punctual. The most often named objects were images and films.

The example above is interesting because it contains one instance of high and one of low transitivity: images "are created" in the head, but the person can also "create your own universe". However, the passive version was rare in the texts.

COMBINING/LINKING/ASSEMBLING

Example: "Assembling. All information and characters must be processed and assembled" (2).

This metaphor is special in that it involves the idea of pre-existing things that have to be assembled in order to form a new thing or collection. The actor acts on this combination rather than the original things that remain unchanged. The action is volitional and telic. Individuation of objects was judged as medium because the students often talked of assembling "information".

\section{COLLECTING}

Example: "a mosaic. While reading, one collects many 'information particles'. From these particles gradually a larger picture emerges" (47).

As in combining, things are important for this metaphor, but transitivity is lower because the combination of things in not in focus. Actor and objects (which are always many) appear rather independent and the objects are often not strongly individuated - the "particles" in the example above are an exception. Volitionality and telos are medium - one can collect information more or less purposefully. The act is extended in time because it is typically repeated.

\section{FINDING}

Example: "Opening a treasure chest. Every book you open brings new knowledge or new insight. At the same time, however, you will also find treasures in novels that can help you escape from everyday life or give you a short holiday" (9). 
In finding, transitivity is rather low; finding rather happens to the person than that $\mathrm{s} /$ he does it, so that it lacks volitionality and telos. The action is punctual, the object is individuated, but not affected by the action.

\section{HOLDING/STORING}

Example: "The brain tries [...] to store the content of what it reads and through this 'film' in the head the content can be reproduced even after some time" (30).

The focus of this metaphor is on not changing things, and the agency of the actor appears in the ability to keep them as they are by holding or storing them. It is a rather common writing metaphor (Scharlau et al., subm.), but much less common in the field of reading. Transitivity is medium: holding/storing is volitional, telic and nonpunctual, but it does not affect the object - indeed is not meant to affect it. PROCESSING

Example: "The difficulty in reading is to be able to absorb, process and then apply information in order to later draw comparisons or to be able to deal critically with what has been read. This is an art that is sometimes very difficult to implement, but you can learn a lot from it" (116).

Processing (German verarbeiten, from arbeiten, to work, working) is a common metaphor in German, also used for writing. It was rare for reading. In terms of spatiality, it always needs a THING. In terms of transitivity, processing indicates a potent actor who does something in a telic, volitional and mostly nonpunctual manner. The object is individuated and highly affected - changed - by the action.

\section{RECEIVING}

Example: "When reading you get a lot of input in a short time" (77).

In receiving, the actor is barely active. The tiny action that is necessary for receiving an object is rarely mentioned in our example, so that transitivity is very low. Although receiving (as transporting) implies an active instance besides the reader, this actor, human or otherwise, was rarely mentioned in our material. This is an illustrative aspect of the absence of others even from those metaphors that imply them. Objects are present, but often neither individuated as the "lot of input" above nor affected by the action that takes place.

\section{TRANSPORTING}

Example: "Scientific books mainly want to impart new knowledge to you" (130).

Transporting is an exception in this system because the metaphor was always used in the passive form (something is conveyed to me) or with texts as an actor (see above). In the everyday events it alludes to, it is similar to receiving, distinctly evoking the impression of something being transported without being affected. It can be regarded as an instance of the conduit metaphor described by Reddy (1971): Communication - in our case written communication - means carrying messages from one to another person. Transitivity is very low, because of the passive expressions used, even lower than in RECEIVING.

\section{STH FORMS}

see above in the description of the group

\section{Moving in or out}

\section{PLUNGING}

see above in the description of the group 


\section{ESCAPING}

Example: "an escape from reality. At first sight, the term 'escape' seems to have a rather negative connotation, but in this sense it is seen as a liberating 'way out' of reality, which is in part exhausting or (personally) stressful" (13).

This conceptual metaphor implies a strong and quick action and some necessity of acting because escape or flight imply something negative that is avoided by the action. The reader may have noted that the metaphorical descriptions are overall rather neutral. This conceptual metaphor is one of the few exceptions. What is left behind is not individuated (reality or everyday life) and not affected. Overall, this is a metaphor of mixed transitivity - the actors can do something and have a goal, but with an effect only on themselves, and they are at least partly pressured to act.

\section{BEING IN STH}

Example: "As soon as some pages are read, one is integrated into the events of the book" (5).

This is a rather pale conceptual metaphor. Agency is very low - some telos and volitionality, but no objects and no effect, often even no action, as in the example above-, but spatiality is characteristic of the moving in/out system.

\section{PUTTING ONESELF INTO}

Example: "When you read (no matter what kind of text it is), you put yourself in the exact position that the text describes or the topic it deals with" (124).

Lexically, this metaphor is similar to BEING IN STH. It has higher transitivity, because the actor does something, even if with an effect only on themselves. Transitivity furthermore differs from other members of this system because the verb is reflexive: The actor appears both as the subject and the object.

\section{SINKING ONESELF INTO}

Example: "When reading, one delves into another world/situation" (13).

"Sich vertiefen", the German expression, is a common metaphor for reading. There is a volitional and telic action; its extendedness in time is indistinct. Instead of the object (which is usually a world or a book/text), the actor is affected, but only temporarily so. Besides the spatial aspect of "in/into", this metaphor has a further distinct spatial dimension, "deep".

Note that this is a category that is difficult to translate. The German expression in all texts is ,sich in etwas vertiefen" which is a reflexive verb and implies the vertical dimension ("tief" = deep). The English translation we chose unfortunately overlaps with the conceptual metaphor SINKING (German "versinken" oder "abtauchen) explained below.

\section{SINKING}

Example: "[...] sink into the world of thoughts" (123)

This conceptual metaphor depicts a very passive actor who lets things happen. If there is an object, it appears as a container or world, as in the example above. Besides the low transitivity, the characteristic aspect of this conceptual metaphor is its spatiality (sinking downwards).

\section{ENTERING}

Example: "Entering another, unknown world" (5).

ENTERING is a volitional, telic and punctual action. The object of action is no thing, but rather a space or world which is neither individuated nor affected. The actor does not seem to be affected either 
although the conceptual metaphor implies some shift in mode of existence. There is some, but not high potency.

\section{LEAVING}

Example: "Reading brings you into a completely new environment. You can leave your everyday life behind you and come to rest" (113).

Leaving puts the distance to something into focus. However, the object is only left behind, not affected. Although as conceptual metaphors, leaving and entering are similarly in transitivity, the example above is typical for our text material because leaving is depicted as something that affects the actor who is relieved from something. The activity has some volitionality and telic aspect. Often, a whole (everyday) life or world is left behind - though only temporarily.

\section{Moving around}

\section{TRAVELING}

see above in the description of the group

EXPLORING

Example: "Reading is like exploring. Through reading, new things are absorbed or perceived. This means that something unknown can be explored through reading" (109).

The metaphor of EXPLORING was mostly used in connection with travel and is therefore placed in the moving category. The activity is telic, volitional and nonpunctual. Different from what one may have expected, the students did not mention things or perspectives to be explored but left the object rather vague, as in the "something unknown" in the example above. In our texts, objects were not individuated. Exploring usually does not affect the object -it should rather leave it unaffected. The actor is not changed either. Overall, thus, transitivity is medium.

\section{MEETING}

Example: "Like on a journey, I encounter things new, familiar, different and adventurous" (86).

The action of meeting can be volitional or telic (as in meeting friends), but can also be something that happens to an actor punctually and that $\mathrm{s} /$ he did not intend to do. Both variants were present in the material. Neither actor no object are affected, so that this conceptual metaphor is of low transitivity. One of the two examples included others (meet persons).

\section{MOVING AROUND}

Example: "Reading is like wandering aimlessly to an unknown destination" (115).

This conceptual metaphor integrates different metaphorical descriptions (walking, wandering, moving). One instance of swimming was also coded as moving around. They are similar in that they depict a person on a long trajectory and were therefore grouped into a single category. Volitionality and aspect vary in our texts - the example above shows this in a conspicuous contradiction: aimless motion towards a goal. The action itself is nonpunctual. Different from the moving into/out of system, the actor is not affected either; they just change their location.

\section{FOLLOWING}

Example: "One forgets the original "effort" of reading and only follows the story" (56).

This is a very rare and almost dead metaphor, as it only appears in the common phrase of "following a story". Although one cannot follow without an action, this action is presented as being controlled and maybe even initiated by an instance different from the actor. 
BEING LED

Example: "Reading is like immersing yourself in another world, because books and texts always lead you into different situations" (46).

Transitivity high, but agency very weak in BEING LED, although it implies: there is no volitionality and no goal. The activity (which is not caused by the person) is nonpunctual. The conceptual metaphor is rather similar to following, but even lower in transitivity.

\section{BACKING AWAY}

Example: "When you read, you can completely hide the 'real' world around you. You can back away from the problems of everyday life and concentrate on this 'other world', where there are no limits to your imagination" (17).

In transitivity, this metaphor is very similar to ESCAPING, but it is more neutral in its emotional aspect. Volitionality and aspect are usually low and the action is punctual. The is an object (often everyday life or reality) is not a grammatical object (backing away from something), and it is not affected by the action.

\section{RECEDING INTO THE BACKGROUND}

Example: "Like on a journey, my current location and my surroundings step into the background. The further I get in the text, the further away they are" (86).

Conceptually, this metaphor is similar to backing away - it results in a distance between the person and an thing or event. In transitivity, however, it is different because it is the object (for instance everyday life or sorrows) are active whereas the person does not do anything.

\section{BEING MOVED}

Example: "be promoted to another world (if the reading is exciting!)" (54).

This is the conceptual metaphor with the lowest transitivity. The actors do not act at all, they are being acted upon. In this aspect, the conceptual metaphor could have been equally placed in the system "being acted upon", but we decided to place it into the "moving around" system because of its distinct spatiality.

\section{MOVING}

Example: "Riding a bike. Once you can ride a bike, you never forget it. It's difficult to think back to the time when you couldn't read yet and had difficulties with it" (31).

This is a metaphor with very little conceptual content, but it was so frequent that we include it in the system. It is in between a metaphor and an explanation. Reading is described as something learned to such a degree that it is automatic. The two examples used were cycling and driving a car.

\section{Being acted upon}

BEING INFLUENCED OR STIMULATED

see group description above

STH AWAITS ME

Example: "For me reading is like an adventure, because you never know what will await you [...]" (82).

This is a category of low transitivity because action is not on the side of the person. The metaphor's transitivity is low in all aspects. 


\section{BEING ENCHAINED}

Example: "If you read a good book, you are completely bound to the created world" (50).

This metaphor has a conventional expression in German ("von einem Buch gefesselt sein", being captivated by a book). Its transitivity is very low although there is some aspect of potency implied: BEING ENCHAINED implies that one cannot do what one would usually do.

\section{BEING CONFRONTED WITH}

Example: “[...] I am [...] confronted with the author's emotional world, motives, and goals in a scientific text" (46).

The semantic difference of being confronted with to encountering is small because in both cases a person (involuntarily) meets an object which poses a difficulty for their action, but there is a grammatical difference because the present metaphor is always passive. Transitivity is again very low.

\section{BEING FORCED}

Example: "the immersion in water. Once you start reading something, you can't concentrate on anything else, just like you can't stop swimming in the water to do something else" (18).

In this metaphor, the person is forced to act against their will. The force is usually left vague as in the present example; it is neither a person nor a thing.

\section{Seeing and opening}

\section{SEEING}

see description of the group above

\section{IMAGINING}

Example: "If you read, only your own imagination plays a role. Everyone imagines the narrated world differently" (50).

IMAGINING mainly differs from SEEING in that the objects seen (the images) are created by the person. Therefore, transitivity is higher in IMAGINING. This is also one of the few metaphors in which there is an object which is affected by the action. Notably, though, in most cases, the texts left the object of imagining vague or abstract, as in the above example ("the narrated world").

\section{TAKING PERSPECTIVES}

Example: "While reading you get a lot of input in a short time. Some information is simply necessary to understand or clarify the whole thing. Others prompt new perspectives or thoughts" (77).

Transitivity of this metaphor is comparable to that of SEEING with the exception of slightly higher kinesis, potency and punctuality. As in the example above, the taking of perspectives may also be of low agency because these new perspectives are enforced on the person by the text. Furthermore, this is one of the very few metaphors in which others were present or at least implied: One takes a different perspective than other persons. As in the example above, the others with the different perspective are often the actors themselves at a different point in time.

This metaphor has a distinct spatiality in that it evokes the idea of a large area and a certain stance which can be shifted or enlarged. One might regard the horizon or the perspective as a containerindeed Lakoff and Johnson (2003, chapter 3), do this when discussing seeing.

\section{BLINDING OUT}

Example: "When you read, you blind out everything else and focus strongly on what is being told" (19). 
In BLINDING OUT, the actor volitionally, but temporarily, blinds out things or even the whole world or everyday life in order to not be affected by them. The objects are not affected by this action. Transitivity still is comparably high. The German expression for this metaphor is "etwas ausblenden" which has a clearly visual source domain and an object. In this, it is different from a related metaphor, SHUTTING OFF (see below, other metaphors).

\section{OPENING}

Example: "Opening a treasure chest. Every book you open brings a new knowledge or new insight. At the same time, however, you will also find treasures in novels that can help you escape from everyday life or give you a short holiday" (9).

The action of OPENING UP is not always one of the actor; possibilities may open up themselves. If there is an action on the part of the reader, it is volitional, telic and punctual. The object may be individuated but it is not affected by the action; thus, the actor is not high in potency. In several of the few instances, the actors are affected by the action in the sense that they gain new insights.

\section{DISCOVERING}

Example: "discovering and getting to know new worlds. The similarities lie in the fact that you always get new information during reading" (100).

Although discovering depends on a person doing something, it is not a strongly transitive action. It is neither telic nor strongly volitional nor extended in time. The actor has low potency. The object is individuated but not affected by the action.

\section{Other metaphors}

\section{BROADENING}

see description of the group above

\section{SHUTTING OFF}

Example: "reading helps me to relax and switch off" (1).

This expression is common in German. Shutting off is an action, but with little transitivity, although it is volitional and telic. Its effect (which is on the actor) is reversible. It can be used transitively (e.g. shutting off one's thoughts) as well as intransitively, and both usages appeared in our texts.

\section{FREEING}

Example: "letting one's imagination run wild" (80).

This is a rare and variable metaphor, mostly characterized by the lexical expression "free" (the German original of the example above is "seiner Fantasie freien Lauf lassen", "freien" = "free"). It implies a weakly agentive action in which the actor volitionally and purposefully releases something from a former state. This something is not substantially changed, and neither is the actor. Others are absent.

\section{BEING FREE}

Example: "You can $[\ldots]$ focus on this 'other world', where there are no limits to your imagination" (17).

As in the example above, this metaphor often came without mentioning an action. The reader is free, even though it remains unclear from what or to which aim. There is almost no transitivity - no action, no object and thus no affectedness. The source domain, however, implies a future high potency of the actor (they could do what they want to). 


\section{LETTING GO}

Example: "let go, drop yourself and immerse yourself in another world" (56).

LETTING GO is a punctual act that can, but needs not, be telic or volitional. Although the German verb is transitive and implies an object, this object was not mentioned in the metaphors. Even if mentioned, the object would not have been affected. The actor is low in potency and the action is rather the absence of action.

\section{WORKING}

Example: "working autonomously or exploring other points of view" (51).

This metaphor depicts the agent as rather high in potency. Interestingly, the object which the actors work on was never mentioned in the (few) examples

\section{DECIPHERING}

Example: "Reading is like deciphering a DNA sequence" (137).

Deciphering (German "entschlüsseln" is partly similar to opening, but in contrast to the latter, it is usually an extended action and it implies a change if not in the object in the relationship between the actor and the object: after deciphering, one understands the nature of the object. The action is telic and volitional and has an individuated object. No others are present.

\section{EXERTING ONESELF}

Example: "Reading is like diving into the depths of the sea and trying to explore and discover them. Fighting through the waves [...]" (106).

In exerting, the actor does something, usually nonpunctually and with a strong effect. The action itself was usually not depicted as strongly voluntarily and has no desired end state (telos). Others are absent. Overall, transitivity is mixed - in some aspects, there is high transitivity (kinesis, temporal extension, affectedness), in others low.

\section{SPEAKING}

Example: "Reading is a form of communication, not with spoken words, but with written words" (33).

This is one of the very few conceptual metaphors that imply others - the authors with whom communication takes place. Transitivity is rather high, except for the absence of an object.

\section{Cognitive and emotion-centered metaphors}

\section{EXPERIENCING, PERCEIVING AND LISTENING}

These are three distinct processes, but similar in transitivity. Activity is at most medium in kinesis, without a clearly present telos or will. The actor does not have potency, and the object is usually unaffected (though the actor may be). Transitivity is as low as for SEEING.

\section{DEALING/GRAPPLING WITH SOMETHING}

Apart from its cognitive 'flavor', this metaphor is very similar to the solidification group: There is an actor who does something in a telic, volitional and nonpunctual manner, but without any effects on the object of action. The German origin ("sich auseinandersetzen") is reflective, which underlines possible effects on the actor. 


\section{QUESTIONING}

Typical for cognitive metaphors, there is an agent, but no individuated object The activity has some telos and volitionality and is nonpunctual. Affectedness is on the side of the actor.

\section{LEARNING}

Learning is an activity. Again, what is affected is the actor, not the object. As in the example above, the object of learning was rarely individuated. Furthermore, the examples depicted learning as something that happens rather than a telic or volitional activity.

\section{FORGETTING}

The forgetting metaphor is a very common German expression in the reading context. Usually the object that is forgotten is daily life or the everyday world. Although forgetting can be seen as volitional, it is not telic, and it is reversible. The object is not affected, and the actor is only temporarily affected.

\section{FOCUSING}

Transitivity is medium: some volitionality and extension in time, also some object, but no affectedness of this object. What is characteristic of this metaphor is the necessary effort on the side of the person.

\section{DREAMING}

Dreaming is not of high kinesis, it is rather something that happens. It is usually not strongly telic and barely volitional, but extended in time. There is no individuated object, rather dreaming is concerned with a whole story.

\section{RELAXING/ENJOYING/FINDING COMFORT}

This category, the only frequent one, has a positive and recreational emotional experience at its core. Transitivity is low because this positive experience is provided and not created. The event is nonpunctual and may be sought for volitionally and purposefully. Others and objects were absent from the descriptions.

\section{NEGATIVE EMOTIONS}

In a few cases, negative experiences were explicitly associated with reading such as stepping on a lego brick or a cave where you cannot see the end. These experience were of course not intended but rather endured.

\section{VACATION}

This is the single clear metaphor in this system; the other categories often are analogies rather than metaphors. VACATION differs from TRAVELING because it was always explained as a relaxing and recreational experience, similar to the relaxing category mentioned above. It was assigned a separate category because it stresses the change of state more than relaxing/enjoying/finding comfort. It was always expressed as a noun and not a verb.

\section{BEING SOMEONE ELSE}

This is a variable category focusing on the activity of being (in) someone else while reading. While the effect of the action is on the reader and not on an object, the action is usually telic, volitional and extended and the actor has at least some potency. Here, others are present, but in a very specific form, not as agents with whom one can interact but as a kind of shell into which one slips.

\section{EMPATHIZING}

This metaphor is very similar to the last one; we assigned it a separate category because the focus was on feeling in empathizing, that is on experiencing the feelings of the person. Furthermore, there is less transitivity because the actor is depicted as passive and suffering from external influences. 